\title{
Studies on temperature characteristics and initial formation interface during cyclopentane-methane hydrate formation in large-scale equipment with bubbling
}

Cai, Jing; Lv, Tao; Zhang, Yu; von Solms, Nicolas; Xu, Chun Gang; Chen, Zhao Yang; Li, Xiao Sen

Published in:

Applied Energy

Link to article, DOI:

10.1016/j.apenergy.2019.114076

Publication date:

2020

Document Version

Publisher's PDF, also known as Version of record

Link back to DTU Orbit

Citation $(A P A)$ :

Cai, J., Lv, T., Zhang, Y., von Solms, N., Xu, C. G., Chen, Z. Y., \& Li, X. S. (2020). Studies on temperature characteristics and initial formation interface during cyclopentane-methane hydrate formation in large-scale equipment with bubbling. Applied Energy, 258, [114076]. https://doi.org/10.1016/j.apenergy.2019.114076

\section{General rights}

Copyright and moral rights for the publications made accessible in the public portal are retained by the authors and/or other copyright owners and it is a condition of accessing publications that users recognise and abide by the legal requirements associated with these rights.

- Users may download and print one copy of any publication from the public portal for the purpose of private study or research.

- You may not further distribute the material or use it for any profit-making activity or commercial gain

- You may freely distribute the URL identifying the publication in the public portal 


\section{Study of temperature characteristics during cyclopentane-}

\section{methane hydrate formation in large-scale equipment with}

\section{bubbling.}

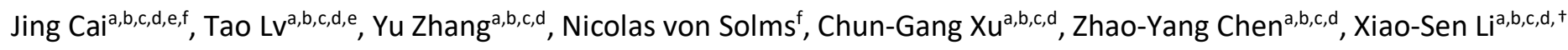

${ }^{a}$ Guangzhou Institute of Energy Conversion, Chinese Academy of Sciences, Guangzhou, 510640, China

${ }^{\mathrm{b} C A S}$ Key Laboratory of Gas Hydrate, Guangzhou, 510640, China

'Guangdong Provincial Key Laboratory of New and Renewable Energy Research and Development, Guangzhou, 510640, China

${ }^{d}$ Guangzhou Center of Gas Hydrate Research, Chinese Academy of Science, Guangzhou, 610640, China

eUniversity of Chinese Academy of Sciences, Beijing, 100049, China

${ }^{f}$ Center for Energy Resources Engineering, Department of Chemical and Biochemical Engineering, Technical University of Denmark, Lyngby, 2800 Kgs., Denmark

\section{Abstract}

In this work, temperature characteristics during hydrate formation were investigated in the cyclopentane-methane system using large-scale equipment with bubbling. The crystallizer volume in each experiment was increased by a factor of 80 compared with previous work. A group of scaled-up experiments, under the optimal condition based on experiments in the smaller crystallizer, was carried out to estimate the scale-up potential of hydrate-based thermal fluid production process. Another group of scaled-up experiments were performed with different variables (volume ratio of cyclopentane to water, gas/liquid ratio and pressure) to understand the initial hydrate formation interface and optimize the temperature of the thermal fluid. Experimental results illustrate that hydrate-based thermal fluid production process can be scaled up by a factor of 80 , however, the temperature of the thermal fluid needs to be optimized by adjusting variables accordingly. Moreover, the liquid cyclopentane/water interface more than the gas/liquid interface affects hydrate formation and hydrate accumulation. In particular, the hydrate formation interface initially occurs on the water side near the liquid cyclopentane/water interface. A large amount of hydrate accumulates in the bulk liquid cyclopentane phase,

\footnotetext{
* The short version of the paper was presented at ICAE2018, Aug 22-25, Hong Kong. This paper is a substantial extension of the short version of the conference paper.

+ Corresponding author. Tel: +86-20-87057037; fax: +86-20-87034664. E-mail address: lixs@ms.giec.ac.cn (X.-S. Li)
} 
forming new hydrate formation interfaces. Thermal fluid with a specific temperature range can be produced based on the heat released and conducted from the hydrate formation interfaces.

\section{Keywords: Temperature characteristics; Heat; Cyclopentane; Hydrate formation interface}

\section{Introduction}

Hydrates are ice-like nonstoichiometric inclusion compounds, which are formed by water molecules (host) and guest molecules, such as light hydrocarbons (gas) under conditions of low temperature and/or high pressure.[1] The framework of host cavities is constructed by water molecules through hydrogen bonds, which are kept stable by encaging guest molecules. For natural gas hydrates (NGHs), guest molecules, including methane $\left(\mathrm{CH}_{4}\right)$, ethane $\left(\mathrm{C}_{2} \mathrm{H}_{6}\right)$, and propane $\left(\mathrm{C}_{3} \mathrm{H}_{8}\right)$, are encaged into host cavities through van der Waals forces, forming NGHs with stable structures. For other multi-hydrates, guest molecules may also include hydrate promoters, such as tetrahydrofuran (THF) $[2,3]$ and cyclopentane (CP),[4-8] and small size gas molecules, such as carbon dioxide $\left(\mathrm{CO}_{2}\right),[9,10]$ and hydrogen $\left(\mathrm{H}_{2}\right)$. [11] Based on the size and property of guest molecule, hydrates can be formed with three types of structure I (sI), structure II (sII), and structure $\mathrm{H}(\mathrm{sH})$. [12]

In nature, sI NGHs have been detected in permafrost and deep marine sediments where NGHs are stable owing to conditions of ample gas supply, suitable temperature and pressure. Since the 1960s, NGHs have gained worldwide attention for two reasons: (1) one cubic meter of $\mathrm{NGHs}$ is equivalent to approximately 160-180 cubic meters of natural gas at standard temperature and pressure (STP), (2) the amount of carbon resource in NGH reservoirs around the world is estimated to be twice that in proven fossil fuels reserves.[1] Thus, NGHs are regarded as a potential energy resource for the future. In order to utilize this abundant energy resource, various NGH exploitation technologies have been investigated. Generally, popular technologies include depressurization,[13-17] thermal stimulation,[18-20] $\mathrm{CH}_{4}-\mathrm{CO}_{2}$ replacement[2127] and chemical stimulation.[28,29] Moreover, several actual production tests have been carried out in NGH reservoirs at Mallik2L-38 in Canada (2008), Alaska (2012), the eastern Nankai Trough of Japan $(2013,2017)$ and the Shenhu sea area in China (2017). Although these tests demonstrated that NGHs could be exploited from NGH reservoirs in permafrost and deep marine sediments, a variety of problems were also encountered in the process of producing $\mathrm{CH}_{4}$ from $\mathrm{NGH}$ reservoirs, such as problems with sand flowing into the well, and unstable gas production, etc. Therefore, further investigation into NGH exploitation technologies is required in order to safely and effectively produce NGHs.

Hot brine injection is a technique that combines the advantages of thermal stimulation and chemical stimulation.[30] By this method, heat can be supplied to decompose NGHs, while the salinity of the injected hot fluid can shift the equilibrium of the NGHs towards a state of more instability. By this combined technology, the exploitation efficiency is thus enhanced. In addition, hydrate formation is an exothermic process. A large amount of heat is released in the process of hydrate formation, especially when hydrates form at a high rate. This heat released during hydrate formation, on the one hand, can be utilized as a heat resource to heat the fluid or to be a heat reservoir in the process. As an example, hydrates are used as a special working medium in air conditioning systems as the hydrates form and dissociate due to the thermal properties.[31] On the other hand, failure to remove this heat of formation rapidly is a drawback to efficient application of hydrate-based technologies for gas separation and water desalination. This is the reason why a refrigerating 
system is always employed to accelerate hydrate formation in hydrate-based techniques. Inspired by the hot brine injection technology and this kind of heat released during hydrate formation, a novel technique was proposed to prepare warm water or brine in situ at the seafloor via a hydrate formation process.[32,33] A conceptual scheme for warm water or brine produced in situ at the seafloor with its attached dual horizontal well system has been detailed previously.[32,34,35] As reported, the heat loss through pipelines can be reduced significantly while energy efficiency can be improved accordingly. Using this method, warm water or brine can be produced in situ at the seafloor via a hydrate formation process as follows.[34] Step 1, add hydrate promoter to the crystallizer located on the seafloor to form multihydrates rapidly under submarine conditions of high pressure and low temperature, producing warm water or brine on the basis of the exothermic and desalination effect associated with multi-hydrate formation. Step 2, inject warm water or brine into NGH reservoir to produce natural gas. Step 3, decompose multi-hydrates at the top of the crystallizer and recycle hydrate promoter after hydrate dissociation. Clearly, this method is beneficial for reducing heat loss and improving energy efficiency.[32] In order to realize this exploitation technique, several obstacles need to be overcome, including determination of an appropriate hydrate promoter, optimization of operating conditions for accelerating hydrate formation, understanding temperature characteristics in the process of hydrate formation, and elimination of hydrate agglomeration for ensuring hydrate slurry mobility in the crystallizer. Cyclopentane (CP) has previously been identified as an appropriate promoter, and methane $\left(\mathrm{CH}_{4}\right)$ has been optimized as the guest.[36-38] In order to find the optimal operating conditions and temperature characteristics, experiments were carried out in the smaller crystallizer with a volume of $125 \mathrm{~mL}$.[34] There, hydrate slurry can be heated up to $294.45 \mathrm{~K}$ from approximately $278.15 \mathrm{~K}$ during experiments. However, in the smaller crystallizer, the temperature gradient across gaseous phase, liquid CP phase and water phase during the hydrate formation could not be clearly distinguished, and it was just assumed that the hydrate formation interface occurred near the gas/liquid CP interface instead of the exact location. According to simulation results, thermal fluid with a temperature of $311.15 \mathrm{~K}$ can be used to exploit NHGs effectively,[39] and the method of preparing warm water or brine in situ at the seafloor was evaluated as a competitive NGH exploitation method for its heating coefficient of 3.0. $[32,40]$ A similar combination exploitation technology of warm water injection and depressurization has been reported, where warm water with a temperature of $303.15 \mathrm{~K}$ could be used to extract natural gas from NGH reservoirs. [41] Therefore, a large amount of warm water or brine needs to be produced with pilot tests based on hydrate formation process, moreover, the temperature characteristics in those tests are necessary to be thoroughly understood.

For retaining heat of formation and subsequently producing thermal fluid, a special insulated large-scale equipment with bubbling was designed and scaled up by a factor of 80 , compared with previous work. $\mathrm{CP}$ and $\mathrm{CH}_{4}$ were still adopted as hydrate promoter and guest, as performed in the smaller crystallizer. [34] Scaled-up experiments were carried out to investigate the temperature characteristics of hydrate slurry and residual water heated by the heat released during hydrate formation. Firstly, the feasibility for enlarging the hydrate-based thermal fluid production process was evaluated. Secondly, the exact hydrate formation interface was determined. Thirdly, the effects of different volume ratios of CP to water, gas/liquid ratio (solution volume) and operating pressures on the temperature of thermal fluid was estimated. The 
same parameters of highest temperature $\left(T_{h}\right)$ and maximum temperate deviation $\left(\Delta T_{\max }\right)$ relative to the initial temperature of $278.15 \mathrm{~K}$ were used here as in the smaller crystallizer. [34]

\section{Experimental section}

\subsection{Materials}

Cyclopentane (CP) with the purity of $99.00 \%$ was supplied by Chengdu Best Reagent Co., Ltd. Methane $\left(\mathrm{CH}_{4}\right)$ with the purity of $99.99 \%$ was supplied by Foshan Huate Special Gas Co., Ltd. Deionized water with a resistivity of $18.25 \mathrm{M} \Omega \cdot \mathrm{cm}^{-1}$ was prepared by ultrapure water equipment GREEN-10T, which was supplied by Nanjing Ultrapure Water Co., Ltd.

\subsection{Apparatus}

A schematic diagram of experimental apparatus is shown in Fig.1. The setup mainly consists of a crystallizer, a gas supply unit, a liquid inlet unit, a low temperature chamber and a data acquisition unit. The crystallizer with inner volume of 10.00 $L$ is made of 316 stainless steel, and it can be rotated with around 90 degree from vertical position towards horizontal position through a fixed trestle. Gas inlet is located at the bottom of crystallizer and gas is introduced into crystallizer through a bubble plate distributor by means of gas bubbling. The maximum pressure of crystallizer is $35.00 \mathrm{MPa}$ in the temperature range of (273.15-323.15) K. This large-scale crystallizer is designed and scaled up by the factor of 80 in terms of the smaller crystallizer, described in the previous work.[34] Same ratio of diameter to height (D/L) of approximately 0.1, same gas/liquid contact method of gas bubbling and same heat insulation method are employed in two crystallizers. For retaining the heat released during hydrate formation, the large-scale crystallizer is also insulated by the insulation layer of aerogel with the heat conductivity coefficient less than $0.02 \mathrm{~W} /(\mathrm{m} \cdot \mathrm{K})$. Moreover, a vacuum insulating layer is also used to improve the heat insulation condition. As shown in Fig. 1, 21 temperature couples are installed at inner wall of crystallizer to measure and monitor temperature during hydrate formation and temperature gradient across gaseous phase, liquid CP phase and water phase. One temperature couple of $\mathrm{T}_{15}$ is installed at outside wall to measure the temperature of crystallizer wall. Take the scaled-up experiment under the optimum obtained in the smaller crystallizer for example, the solution volume of $5.60 \mathrm{~L}$ and the $\mathrm{CP} /$ water volume ratio of $25 / 45$ are adopted in the large-scale crystallizer. $T_{10}, T_{11}$ and $T_{16}$ to $T_{20}$, are located between the gas/liquid CP interface and the liquid CP/water interface, $T_{1}$ to $T_{9}$ are immersed into the bulk water, and $\mathrm{T}_{12}$ to $\mathrm{T}_{14}$ are situated in the gaseous phase. However, for scaled-up experiments among different volume ratio of CP to water and gas/liquid ratio in the large-scale equipment, thermal couples measuring temperature in gaseous phase, liquid CP phase and water phase are changed accordingly, as show in Table 1 . All temperatures in crystallizer, gas supply vessel and chamber are measured by Pt1000 thermal couple (JM6081, Hefei Ding Li Co., Ltd.) with the uncertainly of $\pm 0.05 \mathrm{~K}$. Pressure of crystallizer is measured by pressure transducer (model trafag8251, TRAFAG) with an uncertainty of $0.04 \mathrm{MPa}$. A gas supply unit is applied to maintain the pressure in the crystallizer constant. Gas supply vessel is made of 316 stainless steel with the maximum pressure of $40.00 \mathrm{MPa}$. The pressure in it is measured by pressure transducer (model setra 5310, Setra Systems, Inc.) with an uncertainty of $0.04 \mathrm{MPa}$. A vacuum pump (2XZ-0.5) is used to make admission line air-free. All above mentioned equipment and materials are placed in the low temperature chamber refrigerated by cooled-air circulation refrigeration machine (BSTP-Z500S). The operating temperature of 
chamber is set as $278.15 \mathrm{~K}$ to simulate the seafloor temperature at seawater depth of around $1800 \mathrm{~m}$.[32] Data of pressure and temperature are acquired by a data acquisition system (Agilent 34970), connecting with a computer.

\subsection{Procedure}

Prior to experiments, temperature chamber was set to $278.15 \mathrm{~K}$, equipment and materials $\left(\mathrm{CH}_{4}\right.$ gas $\mathrm{cylinder}, \mathrm{CP}$ and water) were placed in the chamber to precool two days. Deionized water was injected to clean the crystallizer from the top of crystallizer, and washing water was poured out by rotating the crystallizer though the fixed trestle. After the crystallizer was thoroughly washed several times and dried, the desired volume of $\mathrm{CP}$ and water were injected into the crystallizer. After sealing the crystallizer around 30 min later, $\mathrm{CH}_{4}$ gas was introduced into the crystallizer and pressurized up to the desired value with several steps. When gas was introduced through the bubble plate distributor installed at the bottom of crystallizer, gas bubbles with a certain size were generated in bulk water, rising through the liquid CP/water interface and the gas/liquid CP interface. Such gas bubble rising could generate the strong disturbance, which benefited for increasing the contact area and improving the degree of mixing among gas, $\mathrm{CP}$ and water. Due to density of pure $\mathrm{CP}$ hydrate and $\mathrm{CP}-\mathrm{CH}_{4}$ hydrate less than that of water, hydrates ascended along the crystallizer wall spontaneously.[42] Accordingly, temperature in gaseous phase, liquid CP phase and water phase increase because of the heat released in the process hydrate formation. Experiments were completed when temperatures decreased to the ambient temperature. During experiments, when liquid $\mathrm{CP}$ and water were injected into crystallizer, the time was recorded as $\mathrm{t}_{0}$. Computer recorded data of pressure and temperature in real-time. According to the previous work,[34] the amount of heat released in the process of pure $\mathrm{CP}$ hydrate formation was limited, without an obvious effect on hydrate slurry temperature, therefore, no control experiment were performed in the large-scale crystallizer.

To estimate feasibility for enlarging the thermal fluid production process based on hydrate formation, scaled-up experiments were carried out in large-scale crystallizer increased by the factor of 80 under the optimal condition obtained in the smaller crystallizer. This condition included $70 \mathrm{~mL}$ solution with $\mathrm{CP} /$ water volume ratio of $25 / 45$ at $278.15 \mathrm{~K}$ and 8.50 MPa.[34] In this work, volume ration of CP to water is defined as symbol of $R_{v}$, and gas/liquid ratio is defined as symbol of $R_{\mathrm{gl}}$. Thus, it can be modified as the condition with $R_{\mathrm{v}}$ of 0.556 and $R_{\mathrm{gl}}$ of 0.786 at $278.15 \mathrm{~K}$ and $8.50 \mathrm{MPa}$. In addition, $T_{i}$ represents the temperature of thermal couple i (1 to 22 expect 15 ) located inside the crystallizer. Especially, $T_{15}$ represents the temperature of crystallizer outside wall. Same parameters of the highest temperature $\left(T_{h}\right)$ and the maximum temperature deviation ( $\Delta \mathrm{T}_{\max }$ ) were adopted as reported by Cai et al.[34] $\mathrm{T}_{\mathrm{h}-\mathrm{i}}$ and $\Delta \mathrm{T}_{\max -\mathrm{i}}$ represent the highest temperature and the maximum temperature deviation between $T_{h-i}$ and $278.15 \mathrm{~K}$ of thermal fluid, respectively. Effects of different volume ratio of $\mathrm{CP}$ to water, gas/liquid ratio (solution volume) and pressure on hydrate slurry temperature were investigated to optimize the temperature of the thermal fluid.

\section{Results and discussion}

\subsection{Temperature characteristics in the scaled-up experiment}

Scaled-up experiments increased by the factor of 80 were carried out in the large-scale crystallizer with bubbling under the condition with $R_{\sqrt{v}}$ of 0.556 and $R_{\mathrm{gl}}$ of 0.786 at $278.15 \mathrm{~K}$ and $8.50 \mathrm{MPa}$.[34] Temperatures in crystallizer were separated in three different parts, including gaseous phase, the part from the gas/liquid CP interface towards the liquid CP/water 
interface and residual water phase. Temperatures in gaseous phase $\left(T_{11}-T_{14}\right.$ and $\left.T_{16}-T_{17}\right)$ are used to evaluate the heat loss inside the crystallizer. Temperatures in liquid CP phase $\left(T_{10}\right.$ and $\left.T_{18}-T_{22}\right)$ include temperatures between the gas/liquid CP interface and the liquid CP/water interface. Besides, temperatures above the gas/liquid $C P$ interface $\left(T_{11}\right.$ and $\left.T_{17}\right)$ and under the liquid $\mathrm{CP} /$ water interface $\left(T_{9}\right)$ are also included for purpose of evaluating the effect of different interfaces. Temperatures in water phase $\left(T_{1}-T_{9}\right)$ are adopted to estimate thermal fluid produced based on hydrate formation process. In addition, the temperature of outside crystallizer wall $\left(T_{15}\right)$ is used to evaluate the heat loss towards ambient during the experiment.

Fig. 2 shows pressure change in the process of hydrate formation and the highest temperature of hydrate slurry obtained under the condition with $R_{\mathrm{v}}$ of 0.556 and $R_{\mathrm{gl}}$ of 0.786 at $278.15 \mathrm{~K}$ and $8.50 \mathrm{MPa}$. Temperature change of hydrate slurry are related to the amount of the heat released during hydrate formation, the amount of heat conducting along hydrate layer towards residual water, and the amount of heat loss. As detailed in Fig. 2, the hydrate formation rate can be indirectly evaluated by the temperature variation. When the hydrate formation rate is higher, the heat source can be generated in crystallizer by virtue of a large amount of heat released during lots of $\mathrm{CP}-\mathrm{CH}_{4}$ hydrate formation. Meanwhile, such heat is transferring from the hydrate formation interface inside the hydrate layer and towards residual water and ambient by means of heat conduction. Besides, it could be carried into gaseous phase by means of heat convection with gas bubble rising. Therefore, for the heat transferring, it involves into heat conduction inside the hydrate slurry and heat conduction towards residual water. For the heat loss, it involves into the heat conduction towards ambient and the heat convection from the hydrate formation interface or hydrate layer towards gaseous phase. As shown in Fig.2, temperature characteristic is as similar as that reported in the previous work,[34] it illustrates that the heat transferring and heat loss in the large-scale crystallizer are similar with those shown in the smaller crystallizer. However, no obvious stable temperature stage can be found in the large-scale crystallizer. It indicates that the heat conduction from hydrate layer towards residual water is better in the large-scale equipment compared with that in the smaller crystallizer. In sum, the insulation condition is good in the large-scale equipment, and the heat released during hydrate formation can be hold effectively.

According to the highest temperature of hydrate slurry of $292.04 \mathrm{~K}$ at $3840 \mathrm{~min}$, temperature increase and temperature decrease can be observed. From 0 to $3480 \mathrm{~min}$, the value of $T_{20}$ instantly and sharply increase when gas is injected into crystallizer. The pressure fluctuation is resulted from gas injection with several steps to pressurize up to $8.50 \mathrm{MPa}$. Although the temperature fluctuation of $T_{20}$ is synchronous changed with gas injection steps, the weak time lag of the highest temperature for each short fluctuation period can be observed as well. It shows that the heat inside the crystallizer is only released from the $\mathrm{CP}-\mathrm{CH}_{4}$ hydrate formation. Moreover, a large amount of $\mathrm{CP}-\mathrm{CH}_{4}$ hydrates accumulate in bulk liquid CP phase instead of interfaces because the thermal couple of $\mathrm{T}_{20}$ is located in liquid CP phase, between the gas/liquid CP interface and the liquid CP/water interface. This phenomenon is consisted with the results reported in the reference.[43] On the one hand, gas bubble rising leads to a strong perturbation between liquid CP phase and water, resulting in the hydrates was carried into the bulk liquid CP from the liquid CP/water interface. On the other hand, the 
hydrate formation interface is moving towards bulk liquid CP phase due to the density of $\mathrm{CP}-\mathrm{CH}_{4}$ hydrate less than that of water, [42] displaying the climbing growth along crystallizer wall.

Fig. 3 shows temperature change in gaseous phase during hydrate formation. These temperatures in gaseous phase change with the similar trend of the highest hydrate slurry temperature, and the highest gas temperature of $286.43 \mathrm{~K}$ occurs at the same time of $3480 \mathrm{~min}$. This synchronous temperature change testifies that the heat released from the hydrate formation interface can be carried into gaseous phase immediately. Especially, for the temperature of $T_{11}, T_{16}$ and $\mathrm{T}_{17}$ near the gas/liquid CP interface, they show the similar trend with the highest temperature of hydrate slurry. On the contrary, the temperature of $T_{12}, T_{13}$ and $T_{14}$ away from the gas/liquid $C P$ interface shows the impulse change, and no obvious temperature decrease can be found. Both of them indicate that the hydrates grow along the crystallizer wall from the gas/liquid CP interface, resulting in the disappearance of the initial distinct gas/liquid $\mathrm{CP}$ interface during $\mathrm{CP}-\mathrm{CH}_{4}$ hydrate formation. Moreover, the heat can immediately diffuse in gaseous phase. Owing to the heat in the gaseous phase plays no positive effect on enhancing the temperature of thermal fluid, such heat is regarded as inside heat loss.

Fig. 4 shows temperature change in liquid CP phase, including the part between the gas/liquid CP interface and the liquid $\mathrm{CP} /$ water interface during hydrate formation. As detailed in Table 1, the gas/liquid CP interface is located between $\mathrm{T}_{18}$ and $T_{11} / T_{17}$, and the liquid $C P /$ water interface is located between $T_{9}$ and $T_{22}$. Eight thermal couples of $T_{9-11}$ and $T_{18-22}$ are included to investigate temperature change in liquid CP phase. $T_{11}$ and $T_{17}$ are located above the gas/liquid CP interface, and $T_{9}$ is located under the liquid CP/water interface. As shown in Fig. 4, most of temperatures change with the similar trend expect for two temperatures of $T_{9}$ and $T_{22}$ around the liquid $C P /$ water interface. For the temperatures of $T_{9}$ and $T_{22}$, temperature increase before $3480 \mathrm{~min}$, and the obvious stable temperature can be observed from $6600 \mathrm{~min}$ to $17880 \mathrm{~min}$, then, temperatures decrease after $3480 \mathrm{~min}$ as similar as other temperatures. It illustrates that $\mathrm{CP}-\mathrm{CH}_{4}$ hydrates are immediately formed when gas is injected into crystallizer, as same as that detailed in Fig. 3. Moreover, the heat transfers from hydrate formation interface inside the hydrate slurry and towards gaseous phase by means of heat conduction and heat convection, respectively. Meanwhile, hydrate formation interface is moving into liquid CP phase due to the perturbation resulted from gas bubbles rising and the low density of $\mathrm{CP}-\mathrm{CH}_{4}$ hydrate. Consequently, the highest temperature for each thermal couple immersed into liquid CP phase can be measured at around $3480 \mathrm{~min}$. Due to the temperatures of $T_{11}$ and $T_{18-19}$ located in the upper part of liquid CP phase decrease in comparison with those of $T_{10}$ and $T_{20}$ located in the upper part of water. It shows that a large amount of hydrates accumulate in bulk liquid CP phase. However, for $\mathrm{T}_{9}$, an obvious temperature increase can be found before $3480 \mathrm{~min}$. It is relative to the initial occurrence of the hydrate formation interface on the water side near the liquid CP/water interface. It proves that hydrate formation interface is affected by the position of the liquid CP/water interface instead of the gas/liquid interface, which is different with the conclusion drawn in the small crystallizer.[34] In the large-scale crystallizer, it is clear that hydrate formation initially happens on the water side and the liquid CP/water interface significantly rather than the gas/liquid CP interface affects the hydrate formation. Moreover, the thickness of liquid CP affects the mixture degree among gas, liquid CP and water.

Fig. 5 shows the temperature distribution during hydrate formation under the condition with $R_{\mathrm{v}}$ of 0.308 and $R_{\mathrm{gl}}$ of 0.786 at $278.15 \mathrm{~K}$ and $8.50 \mathrm{MPa}$. According to temperature properties, hydrate formation can be divided into four stages with 
similarity as that shown in Fig. 4. Stage 1 ( $a$ to b) is from 0 to $50 \mathrm{~min}$, representing the precooling process before gas injection; stage 2 ( $b$ to c) is from 50 min to $210 \mathrm{~min}$, representing the strong hydrate formation process; stage 3 (c to d) is from $210 \mathrm{~min}$ to $760 \mathrm{~min}$, representing the weak hydrate formation process; and stage 4 ( $\mathrm{d}$ to e) is from $760 \mathrm{~min}$ to 1360 min, representing the hydrate formation completed. From Fig. 5(a) and (b), it can be found that the temperatures in CP phase and water phase are less than approximately $279.15 \mathrm{~K}\left(6^{\circ} \mathrm{C}\right)$, showing the chamber with a good working stability. From Fig. 2(c), the obvious temperature change can be observed between the gas/liquid CP interface and the liquid $\mathrm{CP} /$ water interface. It shows that $\mathrm{CP}-\mathrm{CH}_{4}$ hydrates mainly appear into liquid $\mathrm{CP}$ phase, and the heat can transfer from hydrate formation interface inside the liquid CP phase and conduct towards interfaces, including the gas/liquid interface and the liquid CP/water interface. However, no obvious temperature increase can be found in the gas/liquid CP interface, as same as that detailed in Fig. 4. It also proves that the gas/liquid CP interface hardly affects hydrate formation. From Fig. 2(d), it shows that the heat continuously conducts from the hydrate formation interface towards water phase, heating the bulk water. From Fig. 2(e), the temperature in crystallizer continues to decrease, and no temperature deviation is observed at the end of experiment, showing the end of hydrate formation.

Fig. 6 shows temperature change in water phase in the process of hydrate formation. Temperature in water phase changes with four different stages. Stage $A$ is the initial temperature stable stage, where no hydrates can found even with gas injection. The weak temperature fluctuation may be resulted from the friction heat between gas and water molecules or the heat carried from ambient by gas flow. Around the end of stage $A$, an obvious temperature increase peak of $T_{9}$ and a weak temperature increase of $T_{8}$ can be observed. This highlighted temperature increasing of $T_{9}$ is only resulted from the heat directly released from hydrate formation interface rather than the heat conducted from hydrate formation interface. It further proves that the hydrate formation interface initially occurs on the water phase near the liquid $\mathrm{CP} /$ water interface. For stage $\mathrm{B}$, each temperature significantly increases, but shows the time lag. Especially, the temperature of $\mathrm{T}_{9}$ near the liquid $\mathrm{CP} /$ water interface appears another obvious temperature increasing, and same phenomenon can be found in Stage A. In addition, the obvious time lag among $T_{1}$ to $T_{9}$ means that the heat conduction between the hydrate formation interface and the residual water are always happening during hydrate formation. It involves into not only the heat directly released from hydrate formation interface, but also the heat conducted from hydrate layer. Stage $\mathrm{C}$ is the second temperature stable stage. The deviation among the amount of the heat released from hydrate formation interface in water phase, the amount of heat transferring from hydrate layer by heat conduction and the heat loss from water phase towards ambient. This stage is only shown in water phase because the water with a better specific heat capacity, moreover, a large amount of the residual water can be left because of low hydrate formation rate. On the contrary, the temperature quickly decrease in gas and liquid CP phase after its highest value because the heat could not be hold, meanwhile, directly conducts inside the gaseous phase or the hydrate layer. Stage $D$ is the temperature decrease stage, the obvious time lag can be found from the liquid CP/water interface towards bulk water. The residual water can be heated up by the heat released from hydrate formation interface, and the thermal fluid with a certain temperature range of around ( 280 to 290 ) K can be produced in the large-scale crystallizer with bubbling. Thus, the thermal fluid production based on hydrate formation can be achieved with 80 -fold enlargement. 
Fig. 7 shows temperature change of crystallizer wall monitored by $T_{15}$ in the process of hydrate formation. The temperature shows the similar change with the highest hydrate slurry temperature as shown in Fig. 2 , and the highest value of $281.33 \mathrm{~K}$ is obtained at $4200 \mathrm{~min}$. This temperature involves into heat conducted from the inside crystallizer and heat loss towards ambient, reflecting the heat loss situation of crystallizer. From Table 1, it can be found the highest value of $T_{15}$ is generally below the inside temperature. It illustrates that the heat can be hold to some extent in this large-scale crystallizer, and the crystallizer could be used to produce thermal fluid based on hydrate formation process. Moreover, as described in the conceptual equipment, the large-scale crystallizer will be installed in the seafloor NGH reservoirs. Therefore, such heat loss towards ambient benefits for heating the reservoir during NGH exploitation.[32]

\subsection{Effect of factors on temperature characteristics}

Although hydrate-based thermal fluid production process can be scaled up by the factor of 80 , the highest temperature of $292.04 \mathrm{~K}$ is limited, even less than that obtained in the smaller crystallizer. Therefore, the effect of volume ratios of CP to water, gas/liquid ratio (solution volume) and operating pressures needs to be re-tested to optimize the temperature of the thermal fluid. Experimental runs with different conditions and the position of interfaces, including the gas/liquid interface and the liquid CP/water interface, are summarized in Table 1.

\subsubsection{Effect of volume ratio of CP to water}

For experimental run of 2, 5, 6, 7 and 8, experiments were carried out under the condition of $278.15 \mathrm{~K}$ and $8.50 \mathrm{MPa}$ with a liquid volume of $5.60 \mathrm{~L}$ to investigate effect of $R_{v}$ on temperature characteristic during hydrate formation. The volume ratio of CP to water with $5 / 65,10 / 60,16.5 / 53.5,20 / 50$ and $25 / 45$ is expressed by $R_{v}$ with the value of $0.077,0.167$, $0.308,0.400$ and 0.556 , respectively. Fig. 8 shows the highest temperature under different $R_{v}$, and Table 4 shows the maximum temperature deviation for each thermal couple under different $R_{\mathrm{v}}$. For different $R_{\mathrm{v}}$, the position of the liquid $\mathrm{CP} /$ water interface and the thickness of $\mathrm{CP}$ layer are different, but the gas/liquid CP interfaces are located in the same position.

For the temperature in gaseous phase $\left(\mathrm{T}_{11}-\mathrm{T}_{13}\right)$, the gas temperature obtained with $R_{\mathrm{v}}$ of 0.077 and 0.167 are higher than those obtained with $R_{v}$ of $0.308,0.400$ and 0.506 . It could be resulted from the perturbation degree of gas bubble rising and the position of hydrate formation interface. Under the higher $R_{\mathrm{v}}$, the CP layer is thicker, leading to the main perturbation happened into liquid CP phase more than that in the gaseous phase and water. On the contrary, with the lower $R_{\mathrm{v}}$, the CP layer is thin, and the perturbation happed near the gas/liquid CP interface more than that in the gaseous phase, liquid CP and water. As a result, the hydrate formation interface in the system with lower $R_{v}$ is closer to gaseous phase rather than into the liquid CP phase in the system with higher $R_{\mathrm{v}}$. In addition, the hydrate formation interface always happens near the liquid $\mathrm{CP} /$ water interface, as mentioned in section 3.1. Besides, $\mathrm{CP}-\mathrm{CH}_{4}$ hydrates grow climbing the crystallizer wall. Thus, the heat in the system with lower $R_{\mathrm{v}}$ is easier to be carried into gaseous phase, consequently, the gas temperatures in the system with lower $R_{\mathrm{v}}$ are higher than those obtained in the system with higher $R_{\mathrm{v}}$.

For temperatures near the gas/liquid CP interface, $T_{18}$ shows the highest value of $\Delta T_{\max }$ among $T_{11}, T_{17}$ and $T_{18}$, because $\mathrm{T}_{18}$ is located under the gas/liquid CP interface and immersed into liquid CP phase. Although $\mathrm{T}_{11}$ and $\mathrm{T}_{17}$ are located in the 
similar position, the values of $\Delta \mathrm{T}_{\max }$ are different and significantly lower than that of $\mathrm{T}_{18}$. The highest temperature is obtained with $R_{\vee}$ of 0.308 , and the highest $\Delta \mathrm{T}_{\max }$ of $19.47 \mathrm{~K}$ is achieved near the gas/liquid CP interface. Although the partial hydrates could be formed above the gas/liquid CP interface due to the perturbation of gas bubbles rising and hydrates growth climbing along crystallizer wall, the hydrate formation interfaces mainly occur into liquid CP phase but initially occur near the liquid CP/water interface. It further proves that the hydrate formation interfaces occur into liquid $\mathrm{CP}$ phase. Besides, the perturbation and hydrates growth climbing along crystallizer wall have a certain randomness during hydrate formation. As detailed in Table 1, the liquid CP/water interface with different $R_{\mathrm{v}}$ is displayed in different position, and the liquid CP/water interface moves down with the increase of $R_{\mathrm{v}}$. As shown in Table 3, the highest value of $\Delta \mathrm{T}_{\max }$ is obtained from $\mathrm{T}_{18}$ to $\mathrm{T}_{20}$ with the increase of $R_{\mathrm{v}}$. For instance, the value of $\Delta \mathrm{T}_{\max }$ occurs at $\mathrm{T}_{18}, \mathrm{~T}_{18}, \mathrm{~T}_{18}, \mathrm{~T}_{19}$ and $\mathrm{T}_{20}$ with $R_{\mathrm{v}}$ of $0.077,0.167,0.308,0.400$ and 0.556 , respectively. It indicates that the hydrate formation interface is affected by the liquid CP/water interface and the thickness of liquid CP layer. In addition, the highest temperature $\left(T_{h}\right)$ with $294.15 \mathrm{~K}$, $296.35 \mathrm{~K}, 296.55 \mathrm{~K}, 294.05 \mathrm{~K}$ and $291.95 \mathrm{~K}$ is obtained at the $R_{\mathrm{v}}$ of $0.077,0.167,0.308,0.400$ and 0.556 , respectively. As shown in Fig. 8, the value of increases from 0.077 to 0.308 , and decreases from 0.308 to 0.556 . The optimal $T_{h}$ is obtained at the $R_{v}$ of 0.308 , which is as same as the ideal ratio of $\mathrm{CP}$ to water for $\mathrm{CP}-\mathrm{CH}_{4}$ hydrate $\left(8 \mathrm{CP} \cdot 16 \mathrm{CH}_{4} \cdot 136 \mathrm{H}_{2} \mathrm{O}\right)$. It means that the ideal volume ratio of CP to water is the best $R_{v}$ for releasing more heat in the process of hydrate formation in the large crystallizer. Moreover, the $T_{\mathrm{h}}$ value of $296.35 \mathrm{~K}$ obtained with the $R_{\mathrm{v}}$ of 0.167 also shows an great advantage on releasing more heat during hydrate formation because of less volume of CP needs to be heated up, in comparison with the $R_{\vee}$ of 0.308 .

For water phase $\left(\mathrm{T}_{1}-\mathrm{T}_{9}\right)$, as detailed in Table 3, the temperature of residual water can be heated around (3.18-9.64) $\mathrm{K}$ and (3.07-9.95) $\mathrm{K}$ relative to the initial temperature of $278.15 \mathrm{~K}$ with the $R_{v}$ of 0.308 and 0.556 , respectively. Under the condition with the $R_{v}$ of 0.556 , the temperature of residual water may be not only heated by the heat conducted from the hydrate layer but also heated by the heat released from hydrate formation interfaces, because $T_{9}$ is near the liquid $\mathrm{CP} /$ water interface. Synthesizes the dose of $\mathrm{CP}$ and the temperature of residual water, the $R_{\mathrm{v}}$ of 0.308 is the better volume ratio of $\mathrm{CP}$ to water in this large-scale crystallizer, and will be adopted in the following scaled-up experiments.

\subsubsection{Effect of gas/liquid ratio}

For experimental run of 1, 2, 3, 4 and 5, experiments were carried out under the condition of $278.15 \mathrm{~K}$ and $8.50 \mathrm{MPa}$ with the $R_{\mathrm{v}}$ of 0.308 to investigate effect of $R_{\mathrm{g} \mid}$ on temperature characteristics during hydrate formation. As shown in Table 4 , various $R_{\mathrm{gl}}$ of $0.429,0.786,1.381$ and 2.571 is adopted, and the positon of gas/liquid CP interface is moved down with the increase of $R_{\mathrm{gl}}$ accordingly. The gas/liquid CP interface in the system with $R_{\mathrm{gl}}$ of $0.429,0.786,1.381$ and 2.571 is located between $T_{13}$ and $T_{12} / T_{15}$, between $T_{18}$ and $T_{17} / T_{11}$, between $T_{21}$ and $T_{10} / T_{20}$, and between $T_{7}$ and $T_{8}$, respectively. Fig. 9 shows the highest temperature $\left(\mathrm{T}_{\mathrm{h}}\right)$ under different $R_{\mathrm{gl}}$, and Table 4 shows the maximum temperature deviations $\left(\Delta \mathrm{T}_{\max }\right)$ for each thermal couple relative to the initial temperature of $278.15 \mathrm{~K}$ under different $R_{\mathrm{gl}}$.

For the temperatures in gaseous phase, $T_{13}$ and $T_{14}$ is used to estimate gas temperature during hydrate formation. The similar value of $\Delta \mathrm{T}_{\max }$ for $\mathrm{T}_{13}$ and $\mathrm{T}_{14}$ is obtained under different $R_{\mathrm{gl}}$. It testifies that the heat can be always carried into 
gaseous phase from hydrate formation interface. For the temperatures in liquid CP phase, all temperatures obtained under the gas/liquid CP interface are higher than those obtained above the gas/liquid interface with $R_{\mathrm{gl}}$ from 0.429 to 2.571 except for 1.381. It also proves that the hydrates are mainly formed below the gas/liquid interface. With the $R_{\mathrm{gl}}$ of 1.381, it may be resulted from some gas channels. As detailed in Table 1, the liquid CP/water interface in the system with $R_{\mathrm{gl}}$ of $0.429,0.786,1.381$ and 2.571 is located between $\mathrm{T}_{18}$ and $\mathrm{T}_{11} / \mathrm{T}_{17}$, between $\mathrm{T}_{21}$ and $\mathrm{T}_{10} / \mathrm{T}_{20}$, between $\mathrm{T}_{9}$ and $\mathrm{T}_{8}$, and between $T_{5}$ and $T_{6}$, respectively. The hydrate slurry temperature above the liquid $C P /$ water interface is higher than that under the liquid CP/water interface with different $R_{\mathrm{gl}}$. It illustrates that the hydrates mainly accumulate into the liquid CP phase and above the liquid CP/water interface. As shown in Fig. 9, $T_{\mathrm{h}}$ is with the value of $291.95 \mathrm{~K}, 296.55 \mathrm{~K}, 291.25 \mathrm{~K}$ and $290.55 \mathrm{~K}$ obtained at the position of $\mathrm{T}_{18}, \mathrm{~T}_{18}, \mathrm{~T}_{20}$ and $\mathrm{T}_{7}$ with the $R_{\mathrm{gl}}$ of $0.429,0.786,1.381$ and 2.571 , respectively. $\mathrm{T}_{\mathrm{h}}$ increases from 0.429 to 0.786 , and decreases from 0.786 to 2.571 . It means that the suitable duration of gas bubbles in the water and liquid CP is long enough with the $R_{\mathrm{gl}}$ of 0.786 , resulting in the better perturbation among gas, liquid CP and water. For the $R_{\mathrm{gl}}$ of 0.429 , the thickness of liquid CP limits the perturbation among gas, liquid CP and water. For the $R_{\mathrm{gl}}$ of 1.381 and 2.571, the duration of gas bubbles is too short to generate the enough perturbation among gas, liquid CP and water. As a result, the perturbation limited by the thickness of liquid CP or the duration of gas bubble rising, results in the limited amount of the heat released during hydrate formation. Therefore, the appropriate gas/liquid ratio is important for increasing the highest temperature. Moreover, for the effect on $T_{h}, R_{\mathrm{gl}}$ in the large-scale crystallizer is as same that obtained in the small crystallizer.[34]

In water phase, $\mathrm{T}_{1}$ to $\mathrm{T}_{5}$ is adopted to estimate the temperature of residual water in the systems with different $R_{\mathrm{gl}}$. As shown in Table 4, the higher value of $\Delta \mathrm{T}_{\max }$ can be obtained with higher $R_{\mathrm{gl}}$. It is resulted from that the hydrate formation interface closes to the liquid CP/water interface with higher $R_{\mathrm{gl}}$, and the heat can transfer into residual water in a short time. On the one hand, the amount of hydrates is limited in the system with higher $R_{\mathrm{g}}$, resulting in the limitation of the heat released during hydrate formation. However, on the other hand, the volume of residual water is also limited in the system with higher $R_{\mathrm{gl}}$. As a result, the same gas/liquid ratio is obtained in the large-scale crystallizer with the enlargement of 80 -fold with that obtained in the small crystallizer. The $R_{\mathrm{gl}}$ of 0.786 is helpful to produce thermal fluid in large-scale crystallizer with bubbling.

\subsubsection{Effect of pressure}

For experimental run of 9, 10, 2 and 11, experiments were carried out under the condition of $278.15 \mathrm{~K}$ with $R_{\mathrm{v}}$ of 0.308 and $R_{\mathrm{gl}}$ of 0.786 to investigate effect of different pressures on temperature characteristics during hydrate formation. Fig. 10 shows the highest temperature $\left(T_{h}\right)$ under different pressures. Table 5 shows the maximum temperature deviation $\left(\Delta T_{\max }\right)$ for each thermal couple relative to the initial temperature of $278.15 \mathrm{~K}$. Due to the fixed positions of the gas/liquid $\mathrm{CP}$ interface and the liquid CP/water interface under different pressures, only the highest temperature of hydrate slurry and the temperature of water phase are compared. As shown in Table 5, the value of $\Delta T_{\max }$ for residual water $\left(T_{1}-T_{9}\right)$ increases with the increase of pressure. Moreover, the residual water can be enhanced around (5.67-16.34) K from 278.15 $\mathrm{K}$ at the pressure of $12.00 \mathrm{MPa}$. Accordingly, $\mathrm{T}_{\mathrm{h}}$ increases from $281.35 \mathrm{~K}$ to $304.05 \mathrm{~K}$ with the increase of pressure from 2.50 MPa to $12.00 \mathrm{MPa}$. Both the increase of $\mathrm{T}_{\mathrm{h}}$ and $\Delta \mathrm{T}_{\max }$ with pressure illustrate that the thermal fluid with desired 
temperature can be achieved and optimized by controlling the pressure directly under the suitable $R_{\mathrm{v}}$ and $R_{\mathrm{gl}}$. Therefore, the highest hydrate slurry temperature of $304.05 \mathrm{~K}$ and the warm residual water in the temperature range of (282.82293.47) K can be obtained under the $R_{v}$ of 0.308 and the $R_{\mathrm{gl}}$ of 0.786 . This temperature of thermal fluid is in the proper temperature range, which was adopted for NGH exploitation combining with depressurization.[23]

\section{Conclusions}

In this work, temperature characteristics of hydrate slurry related to heat released during cyclopentane-methane hydrate formation were investigated in the large-scale equipment with bubbling, where the scale was increased by the factor of 80 and the similar diameter to height ratio was adopted in comparison with the previous work. A group of scaledup experiments were carried out with the optimal condition obtained in smaller crystallizer to estimate enlargement feasibility for producing thermal fluid based on hydrate formation process. Another group of scaled-up experiments were performed to evaluate the effect of different interfaces on the hydrate formation interface and to produce the thermal fluid with certain temperature under different conditions. Experimental results prove that the hydrate-based thermal fluid production process can be enlarged successfully, however, the condition needs to be re-tested for producing the thermal fluid with desired temperature in the different scale crystallizer. Especially, same gas/liquid ratio of 0.308 can be directly adopted, however, the volume ratio of cyclopentane to water needs to be re-tested. The highest temperature of thermal fluid can be directly optimized by increasing the pressure. In addition, it is found that the hydrate formation interface initially occurs on the water side near the liquid cyclopentane/water interface, while the gas/liquid interface has no obvious effect on hydrate formation interface. Moreover, a large amount of hydrates accumulates in the liquid cyclopentane phase, showing new hydrate formation interfaces. The thermal fluid with certain temperature range can be produced during cyclopentane-methane hydrate formation. This conclusion gives a positive guideline for enlarging the hydrate-based thermal fluid production. Such thermal fluid could be used into the hot water injection for exploiting NHGs or other combination exploitation technologies.

\section{Acknowledgements}

This work was supported by Key Program of National Natural Science Foundation of China (51736009), Special Project for Marine Economy Development of Guangdong Province (GDME-2018d002), National Science Fund for International S\&T Cooperation Program of China (2015DFA61790), National Key Research and Development Plan of China (2016YFC0304002, 2017YFC0307306), Science and Technology Apparatus Development Program of the Chinese Academy of Sciences (YZ201619), Frontier Sciences Key Research Program of the Chinese Academy of Sciences (QYZDJ-SSW-JSC033) and China Scholarship Council (CSC201804910598).

\section{References}

[1] Sloan ED, Koh CA. Hydrate Formation and Dissociation Processes. Clathrate Hydrates Nat Gases 2008. doi:10.1201/9781420008494.ch3.

[2] Cai J, Zhang Y, Xu CG, Xia ZM, Chen ZY, Li X Sen. Raman spectroscopic studies on carbon dioxide separation from 
fuel gas via clathrate hydrate in the presence of tetrahydrofuran. Appl Energy 2018. doi:10.1016/j.apenergy.2018.01.055.

[3] Zheng J, Zhang P, Linga P. Semiclathrate hydrate process for pre-combustion capture of CO2at near ambient temperatures. Appl Energy 2017. doi:10.1016/j.apenergy.2016.10.118.

[4] Veluswamy HP, Chin WI, Linga P. Clathrate hydrates for hydrogen storage: The impact of tetrahydrofuran, tetran-butylammonium bromide and cyclopentane as promoters on the macroscopic kinetics. Int J Hydrogen Energy 2014. doi:10.1016/j.ijhydene.2014.01.054.

[5] Daraboina N, Von Solms N. The combined effect of thermodynamic promoters tetrahydrofuran and cyclopentane on the kinetics of flue gas hydrate formation. J Chem Eng Data 2015. doi:10.1021/je500529w.

[6] Ho LC, Babu P, Kumar R, Linga P. HBGS (hydrate based gas separation) process for carbon dioxide capture employing an unstirred reactor with cyclopentane. Energy 2013. doi:10.1016/j.energy.2013.10.031.

[7] Zhang J, Yedlapalli P, Lee JW. Thermodynamic analysis of hydrate-based pre-combustion capture of CO2. Chem Eng Sci 2009. doi:10.1016/j.ces.2009.04.041.

[8] Zhong DL, Daraboina N, Englezos P. Recovery of $\mathrm{CH} 4$ from coal mine model gas mixture (CH4/N2) by hydrate crystallization in the presence of cyclopentane. Fuel 2013. doi:10.1016/j.fuel.2013.01.029.

[9] Li X Sen, Xu CG, Chen ZY, Cai J. Synergic effect of cyclopentane and tetra-n-butyl ammonium bromide on hydratebased carbon dioxide separation from fuel gas mixture by measurements of gas uptake and X-ray diffraction patterns. Int J Hydrogen Energy 2012. doi:10.1016/j.ijhydene.2011.09.053.

[10] Mohammadi AH, Eslamimanesh A, Belandria V, Richon D. Phase equilibria of semiclathrate hydrates of CO2, N 2, CH4, or H2 + Tetra-n-butylammonium bromide aqueous solution. J Chem Eng Data 2011. doi:10.1021/je2005159.

[11] Mao WL, Mao H. Hydrogen storage in molecular compounds. PNAS 2004. doi:10.1073/pnas.0307449100.

[12] Englezos P. Clathrate Hydrates. Ind Eng Chem Res 1993. doi:10.1021/ie00019a001.

[13] Xiong L, Li X, Wang Y, Xu C. Experimental study on methane hydrate dissociation by depressurization in porous sediments. Energies 2012. doi:10.3390/en5020518.

[14] Tang LG, Li X Sen, Feng ZP, Li G, Fan SS. Control mechanisms for gas hydrate production by depressurization in different scale hydrate reservoirs. Energy and Fuels 2007. doi:10.1021/ef0601869.

[15] Moridis G, Kowalsky M, Pruess K. Depressurization-Induced Gas Production From Class 1 Hydrate Deposits. SPE Reserv Eval Eng 2007. doi:10.2118/97266-PA.

[16] Konno Y, Oyama H, Nagao J, Masuda Y, Kurihara M. Numerical analysis of the dissociation experiment of naturally occurring gas hydrate in sediment cores obtained at the eastern nankai trough, Japan. Energy and Fuels 2010. 
doi:10.1021/ef1008727.

[17] Konno Y, Masuda Y, Hariguchi Y, Kurihara M, Ouchi H. Key factors for depressurization-induced gas production from oceanic methane hydrates. Energy and Fuels 2010. doi:10.1021/ef901115h.

[18] Li G, Moridis GJ, Zhang K, Li X sen. The use of huff and puff method in a single horizontal well in gas production from marine gas hydrate deposits in the Shenhu Area of South China Sea. J Pet Sci Eng 2011. doi:10.1016/j.petrol.2011.02.009.

[19] Cranganu C. In-situ thermal stimulation of gas hydrates. J Pet Sci Eng 2009. doi:10.1016/j.petrol.2008.12.028.

[20] Jin Y, Li S, Yang D, Jiang X. Determination of dissociation front and operational optimization for hydrate development by combining depressurization and hot brine stimulation. J Nat Gas Sci Eng 2018. doi:10.1016/j.jngse.2017.12.009.

[21] Mu L, Von Solms N. Methane Production and Carbon Capture by Hydrate Swapping. Energy and Fuels 2017. doi:10.1021/acs.energyfuels.6b01638.

[22] Mu L, von Solms N. Hydrate thermal dissociation behavior and dissociation enthalpies in methane-carbon dioxide swapping process. J Chem Thermodyn 2018. doi:10.1016/j.jct.2017.08.018

[23] Wang B, Dong H, Liu Y, Lv X, Liu Y, Zhao J, et al. Evaluation of thermal stimulation on gas production from depressurized methane hydrate deposits次. Appl Energy 2018. doi:10.1016/j.apenergy.2017.08.005.

[24] Komatsu H, Ota M, Smith RL, Inomata H. Review of $\mathrm{CO} 2-\mathrm{CH} 4$ clathrate hydrate replacement reaction laboratory studies - Properties and kinetics. J Taiwan Inst Chem Eng 2013. doi:10.1016/j.jtice.2013.03.010.

[25] Zhao J, Xu K, Song Y, Liu W, Lam W, Liu Y, et al. A Review on Research on Replacement of CH4 in Natural Gas Hydrates by Use of CO2. Energies 2012. doi:10.3390/en5020399.

[26] Lee Y, Kim Y, Lee J, Lee H, Seo Y. CH4 recovery and CO2 sequestration using flue gas in natural gas hydrates as revealed by a micro-differential scanning calorimeter. Appl Energy 2015. doi:10.1016/j.apenergy.2015.04.012.

[27] Mu L, Von Solms N. Experimental Study on Methane Production from Hydrate-Bearing Sandstone by Flue Gas Swapping. Energy and Fuels 2018. doi:10.1021/acs.energyfuels.8b01437.

[28] Dong F-H, Zang X-Y, Fan S-S, Liang D-Q. Experimental simulation on dissociation behavior of propane hydrate by methanol glycol solution injection. Shiyou Huagong Gaodeng Xuexiao Xuebao/Journal Petrochemical Univ 2009. doi:10.3696/j.issn.1006-396X.2009.03.003.

[29] Elgibaly A, Elkamel A. Optimal hydrate inhibition policies with the aid of neural networks. Energy and Fuels 1999. doi:10.1021/ef980129i.

[30] Li X Sen, Wan LH, Li G, Li QP, Chen ZY, Yan KF. Experimental investigation into the production behavior of 
methane hydrate in porous sediment with hot brine stimulation. Ind Eng Chem Res 2008. doi:10.1021/ie8009582.

[31] Wang X, Dennis M, Hou L. Clathrate hydrate technology for cold storage in air conditioning systems. Renew Sustain Energy Rev 2014. doi:10.1016/j.rser.2014.04.032.

[32] Chen Z, Feng J, Li X, Zhang Y, Li B, Lv Q. Preparation of warm brine in situ seafloor based on the hydrate process for marine gas hydrate thermal stimulation. Ind Eng Chem Res 2014. doi:10.1021/ie501181r.

[33] Li X Sen, Xu CG, Zhang Y, Ruan XK, Li G, Wang Y. Investigation into gas production from natural gas hydrate: A review. Appl Energy 2016. doi:10.1016/j.apenergy.2016.03.101.

[34] Cai J, Hu YF, Zhang Y, Xu CG, Chen ZY, Lv QN, et al. Study on Temperature Characteristics of Hydrate Slurry during Cyclopentane-Methane Hydrate Formation. Energy and Fuels 2018. doi:10.1021/acs.energyfuels.7b03655.

[35] Zang X, Lv Q, Li X, Li G. Experimental investigation on cyclopentane-methane hydrate formation kinetics in brine. Energy and Fuels 2017. doi:10.1021/acs.energyfuels.6b02435.

[36] Lv QN, Li X Sen, Chen ZY. Formation of cyclopentane - methane hydrates in brine systems and characteristics of dissolved ions. Appl Energy 2016. doi:10.1016/j.apenergy.2016.10.035.

[37] Lv QN, Li X Sen, Chen ZY, Feng JC. Phase equilibrium and dissociation enthalpies for hydrates of various waterinsoluble organic promoters with methane. J Chem Eng Data 2013. doi:10.1021/je4007025.

[38] Lv Q, Li L, Li X, Chen Z. Formation Kinetics of Cyclopentane + Methane Hydrates in Brine Water Systems and Raman Spectroscopic Analysis. Energy and Fuels 2015. doi:10.1021/acs.energyfuels.5b01416.

[39] Feng JC, Wang Y, Li X Sen, Chen ZY, Li G, Zhang Y. Investigation into optimization condition of thermal stimulation for hydrate dissociation in the sandy reservoir. Appl Energy 2015. doi:10.1016/j.apenergy.2015.05.106.

[40] Song Y, Cheng C, Zhao J, Zhu Z, Liu W, Yang M, et al. Evaluation of gas production from methane hydrates using depressurization, thermal stimulation and combined methods. Appl Energy 2015. doi:10.1016/j.apenergy.2015.02.040.

[41] Phirani J, Mohanty KK, Hirasaki GJ. Warm water flooding of unconfined gas hydrate reservoirs. Energy and Fuels 2009. doi:10.1021/ef900291j.

[42] Chong ZR, Yang SHB, Babu P, Linga P, Li X Sen. Review of natural gas hydrates as an energy resource: Prospects and challenges. Appl Energy 2016. doi:10.1016/j.apenergy.2014.12.061.

[43] Lim YA, Babu P, Kumar R, Linga P. Morphology of carbon dioxide-hydrogen-cyclopentane hydrates with or without sodium dodecyl sulfate. Cryst Growth Des 2013;13:2047-59. doi:10.1021/cg400118p. 


\section{Figure and Table Caption}

Fig. 1 Schematic of experimental apparatus.

Fig. 2 The change of temperature with the highest value during hydrate formation.

Fig. 3 The change of temperatures in gaseous phase during hydrate formation.

Fig. 4 The change of temperatures in liquid CP phase during hydrate formation.

Fig. 5 Temperature distribution in the process of hydrate formation under condition of $278.15 \mathrm{~K}$ and $8.50 \mathrm{MPa}$ with the CP to water volume ratio $\left(R_{\mathrm{v}}\right)$ of 0.308 . a, 0; b, $50 \mathrm{~min} ; \mathrm{c}, 210 \mathrm{~min}$;, $760 \mathrm{~min} ; \mathrm{e}, 1360 \mathrm{~min}$.

Fig. 6 The change of temperatures in water phase during hydrate formation.

Fig.7 The change of temperature on the crystallizer wall during hydrate formation.

Fig. 8 The highest hydrate slurry temperature $\left(T_{h}\right)$ obtained in different volume ratio of CP to water $\left(R_{v}\right)$.

Fig. 9 The highest hydrate slurry temperature $\left(T_{h}\right)$ obtained in different gas/liquid volume ratio $\left(R_{\mathrm{gl}}\right)$.

Fig. 10 The highest hydrate slurry temperature $\left(T_{h}\right)$ obtained in different pressures.

Table 1. Data of $\Delta \mathrm{T}_{\max }$ and positions of gas/liquid CP interface and liquid/water interface under different conditions.

Table 2. Data of $\mathrm{T}_{\mathrm{h}}$ and $\Delta \mathrm{T}_{\max }$ obtained at different position under the condition with $R_{\mathrm{v}}$ of 0.556 and $R_{\mathrm{gl}}$ of 0.786 at $278.15 \mathrm{~K}$ and $8.50 \mathrm{MPa}$.

Table 3. Data of $\Delta \mathrm{T}_{\max }$ for each thermal couple in the process of hydrate formation under different volume ratio of $\mathrm{CP}$ to water $\left(R_{\mathrm{v}}\right)$.

Table 4. Data of $\Delta \mathrm{T}_{\max }$ for each thermal couple in the process of hydrate formation under different gas/liquid ratio $\left(R_{\mathrm{gl}}\right)$.

Table 5. Data of $\Delta T_{\max }$ for each thermal couple in the process of hydrate formation under different pressures. 


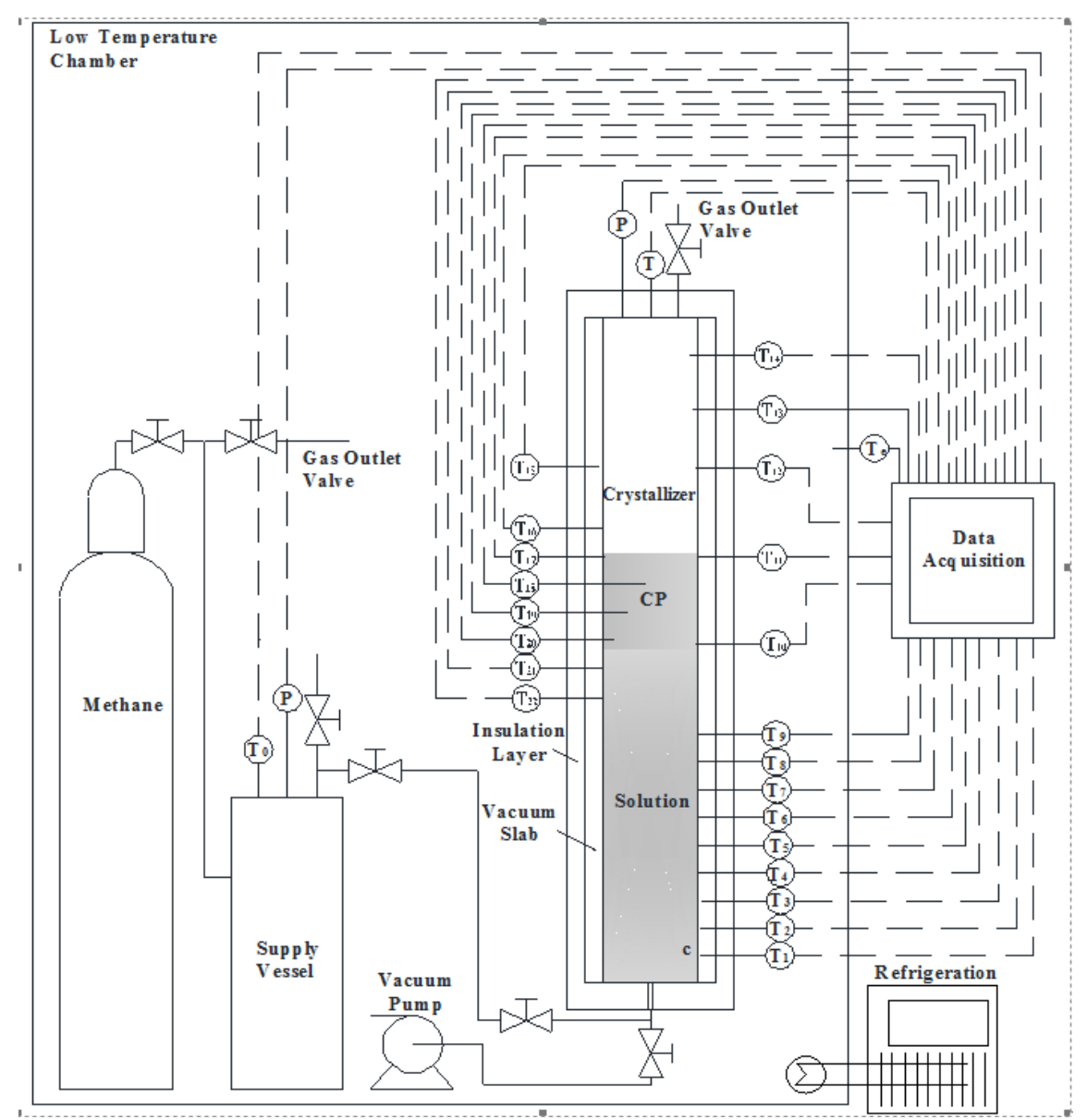

Fig. 1. Schematic of experimental apparatus.

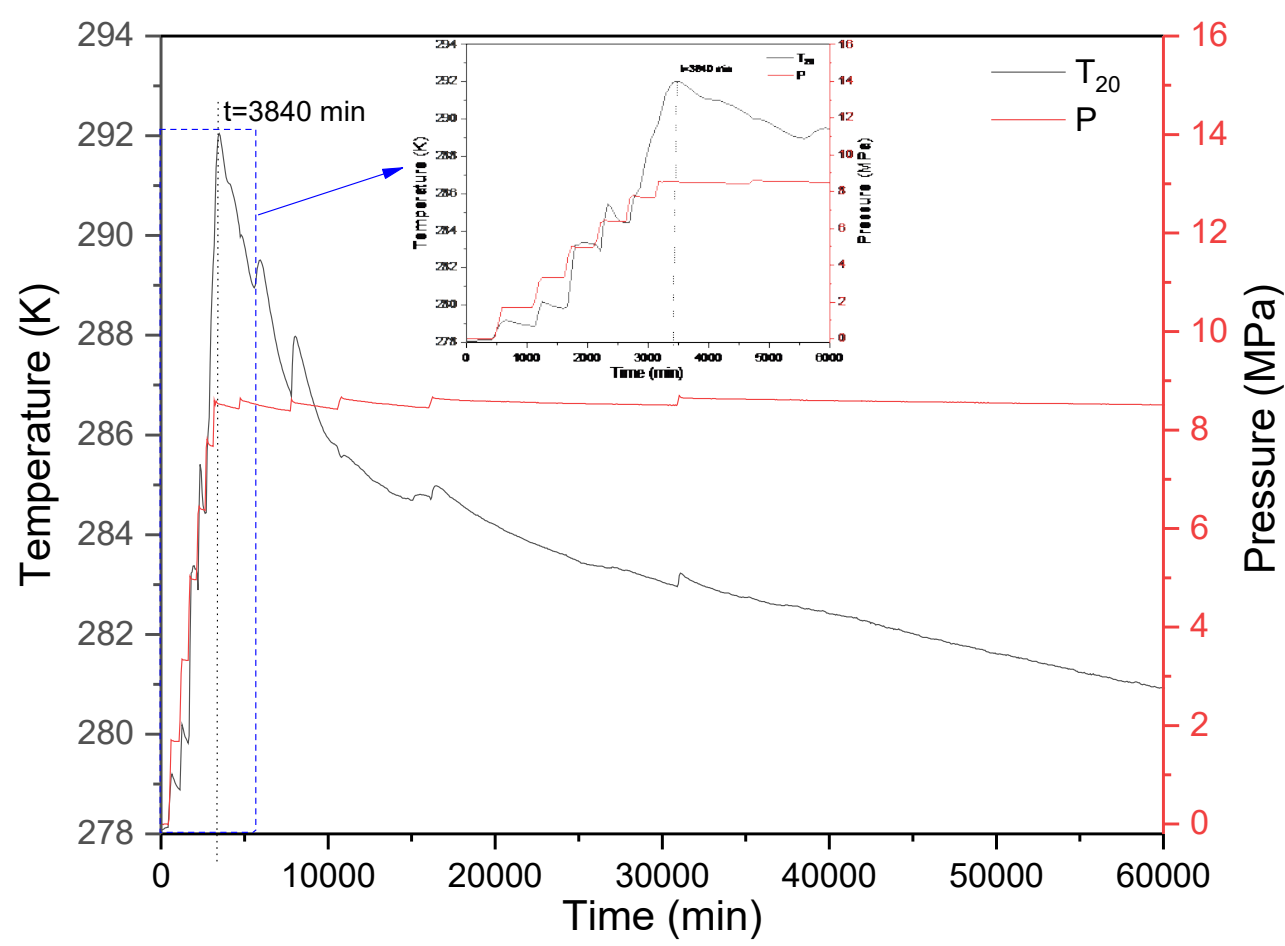


Fig. 2 The change of temperature with the highest value during hydrate formation.

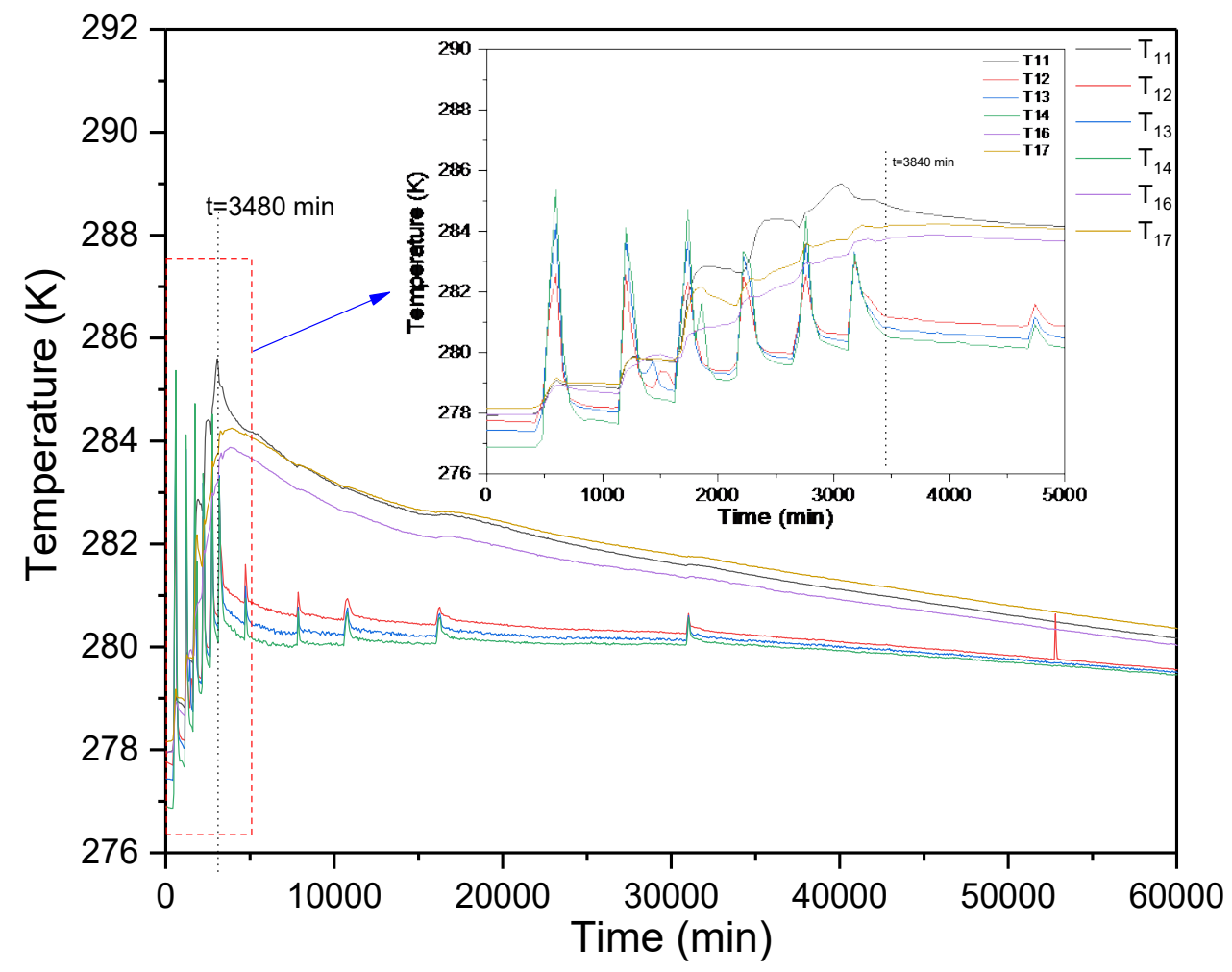

Fig. 3 The change of temperatures in gaseous phase during hydrate formation

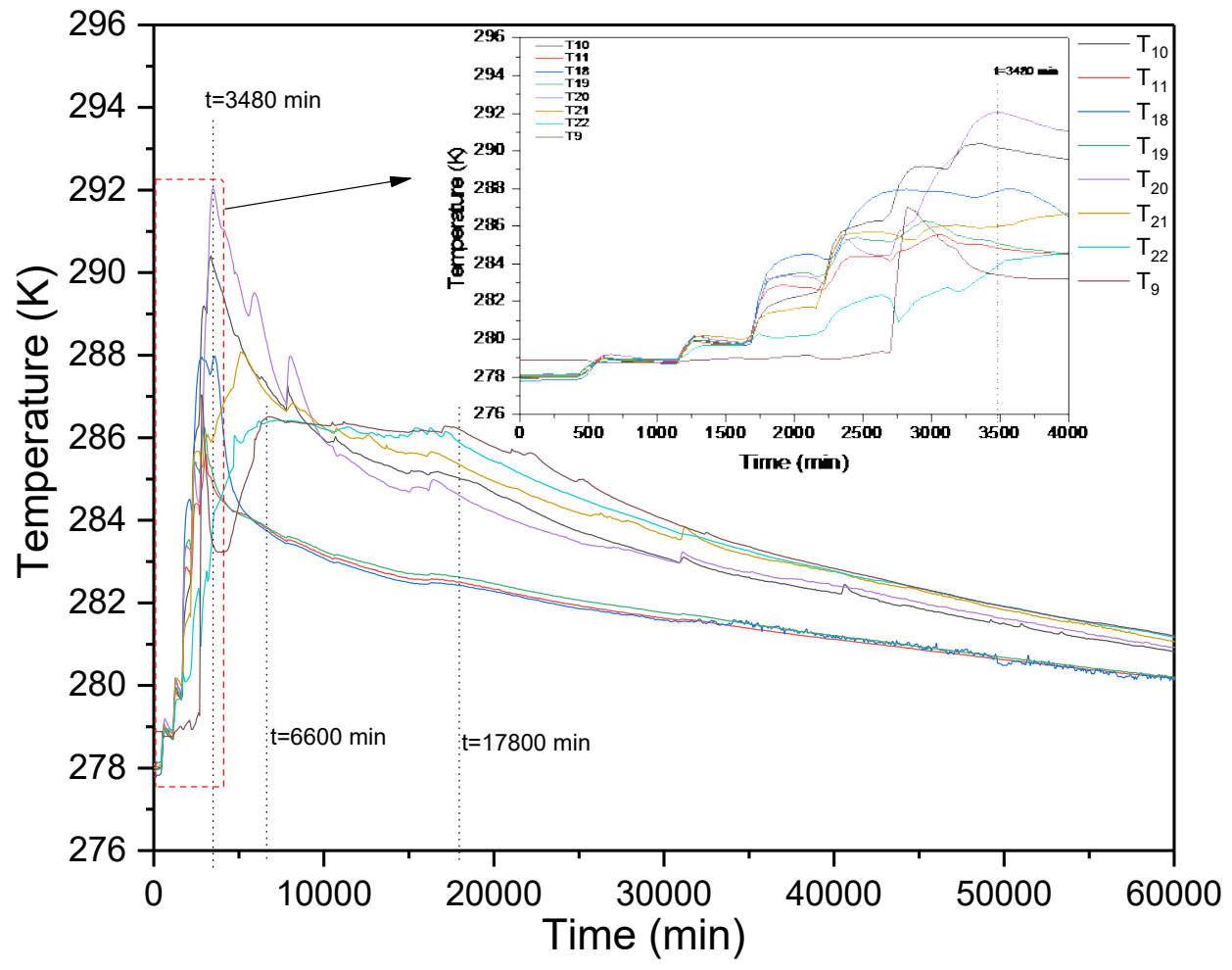

Fig. 4 The change of temperatures in liquid CP phase during hydrate formation. 

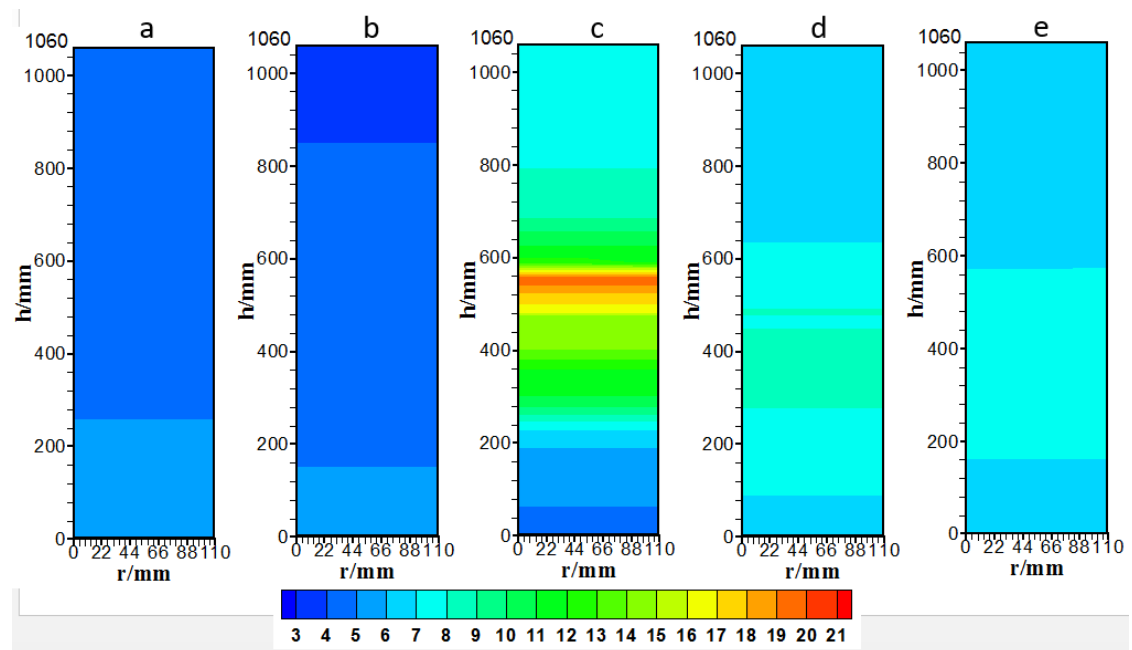

Fig. 5 Temperature distribution in the process of hydrate formation under condition of $278.15 \mathrm{~K}$ and $8.50 \mathrm{MPa}$ with $R_{\vee}$ of 0.308. a, 0; b, $50 \mathrm{~min} ; \mathrm{c}, 210 \mathrm{~min} ; \mathrm{d}, 760 \mathrm{~min} ; \mathrm{e}, 1360 \mathrm{~min}$.

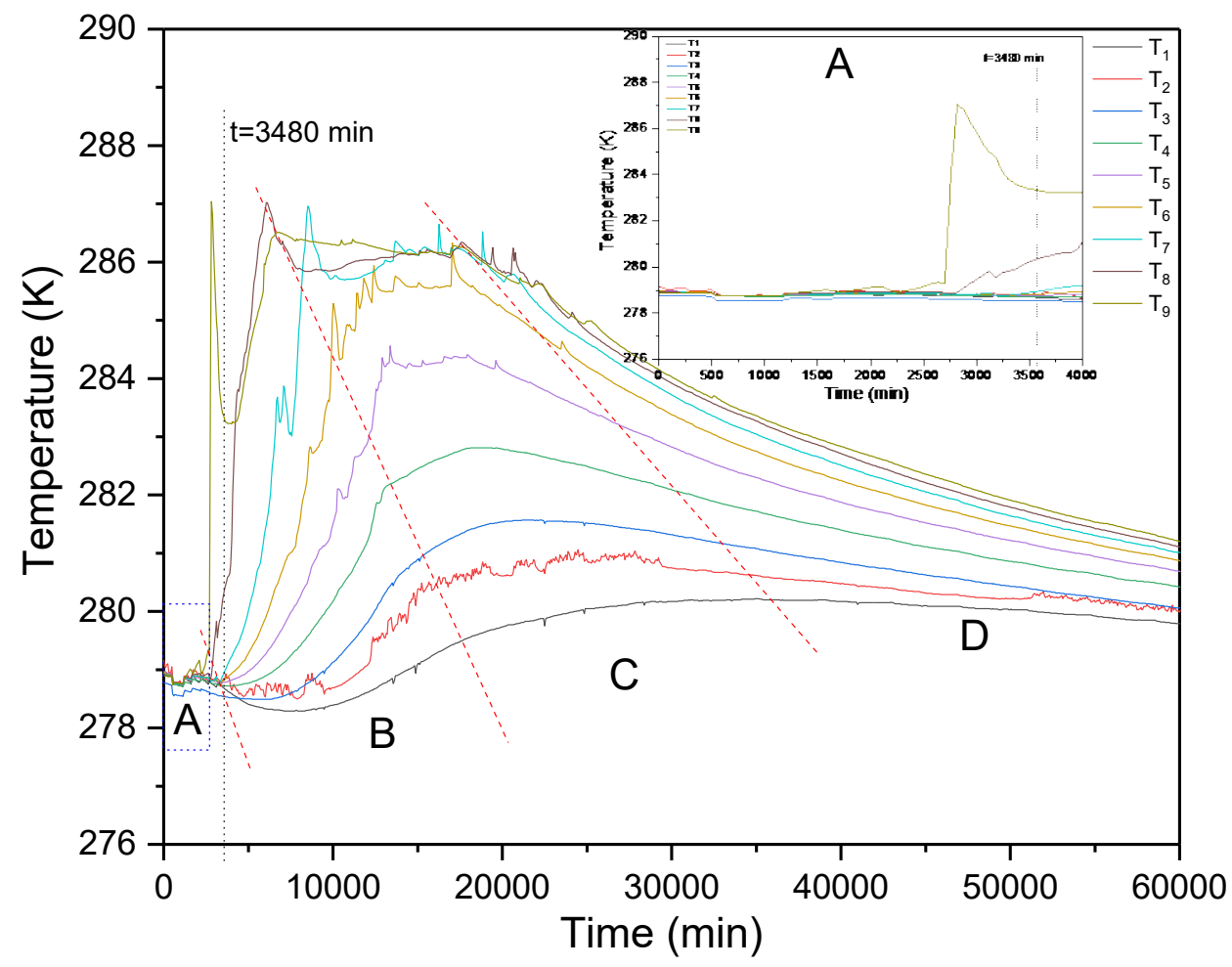

Fig. 6 The change of temperatures in water phase during hydrate formation. 


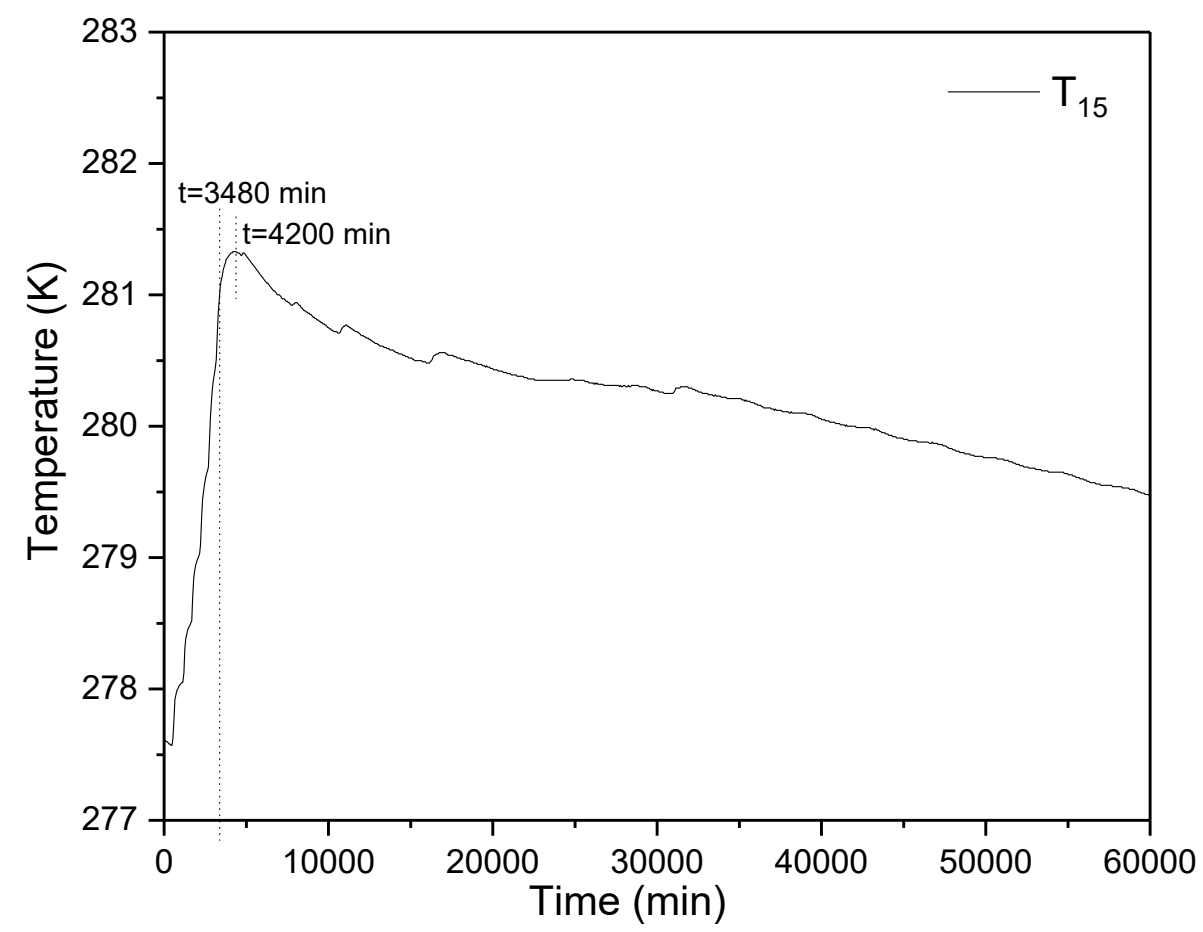

Fig. 7 The change of temperature on the crystallizer wall during hydrate formation.

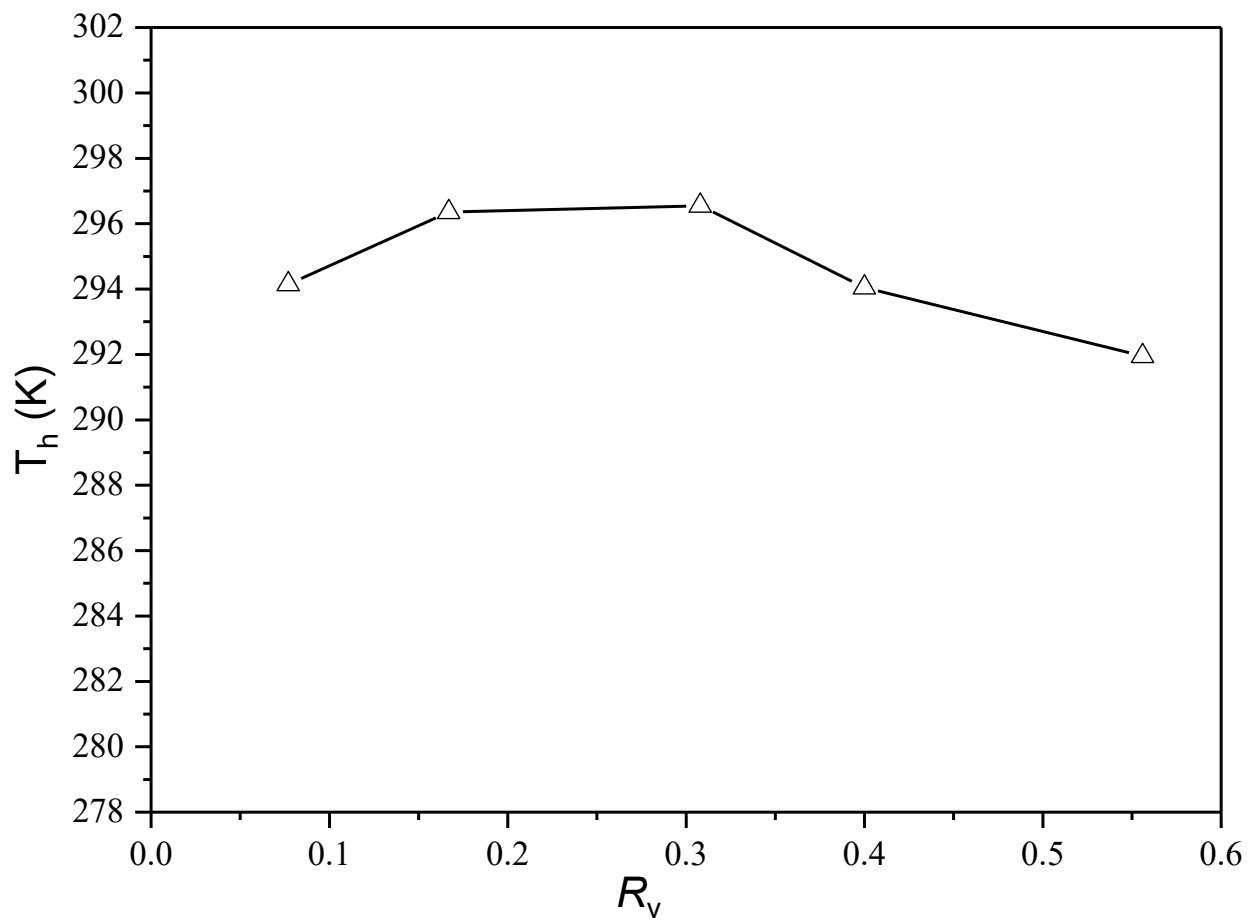

Fig. 8 The highest hydrate slurry temperature $\left(\mathrm{T}_{\mathrm{h}}\right)$ obtained in different volume ratio of CP to water $\left(R_{\mathrm{v}}\right)$. 


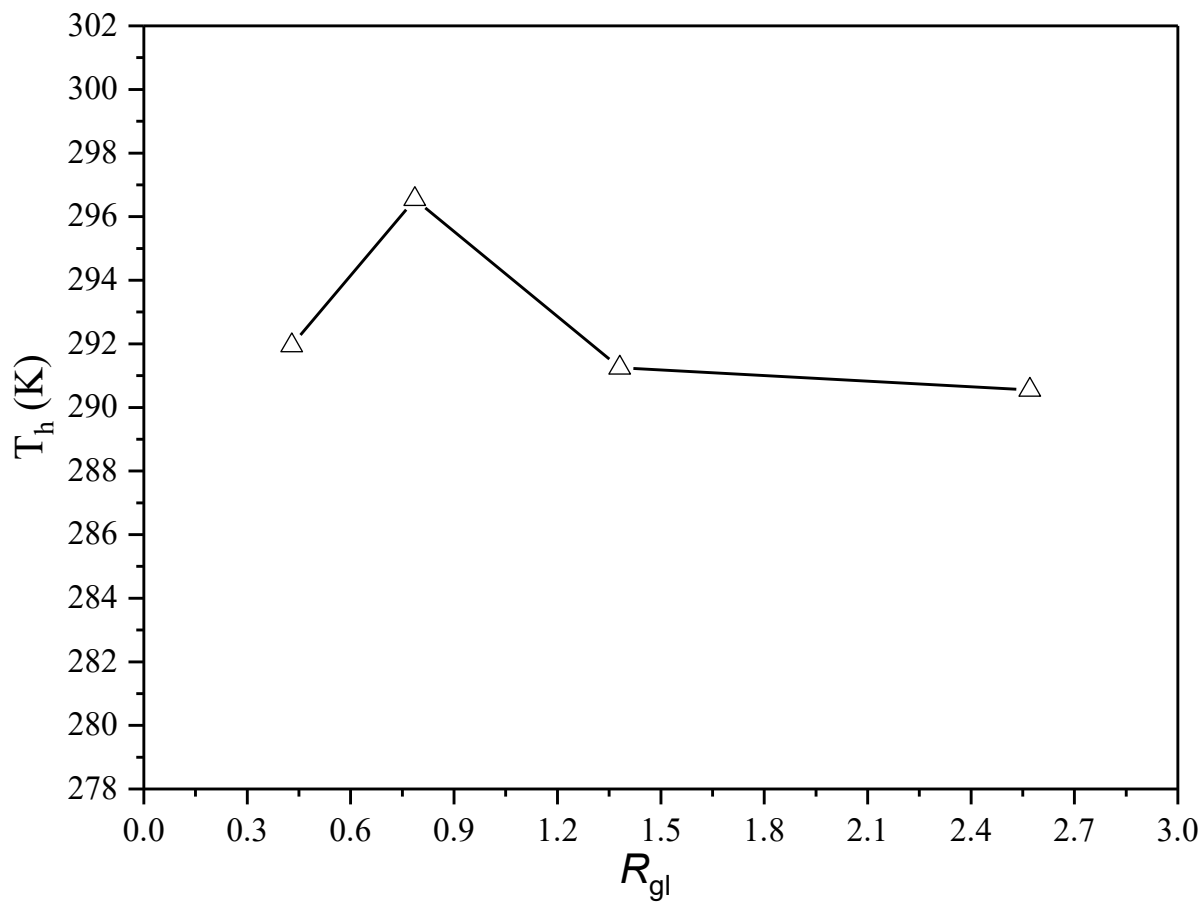

Fig. 9. The highest hydrate slurry temperature $\left(T_{h}\right)$ obtained in different gas/liquid volume ratio $\left(R_{\mathrm{gl}}\right)$.

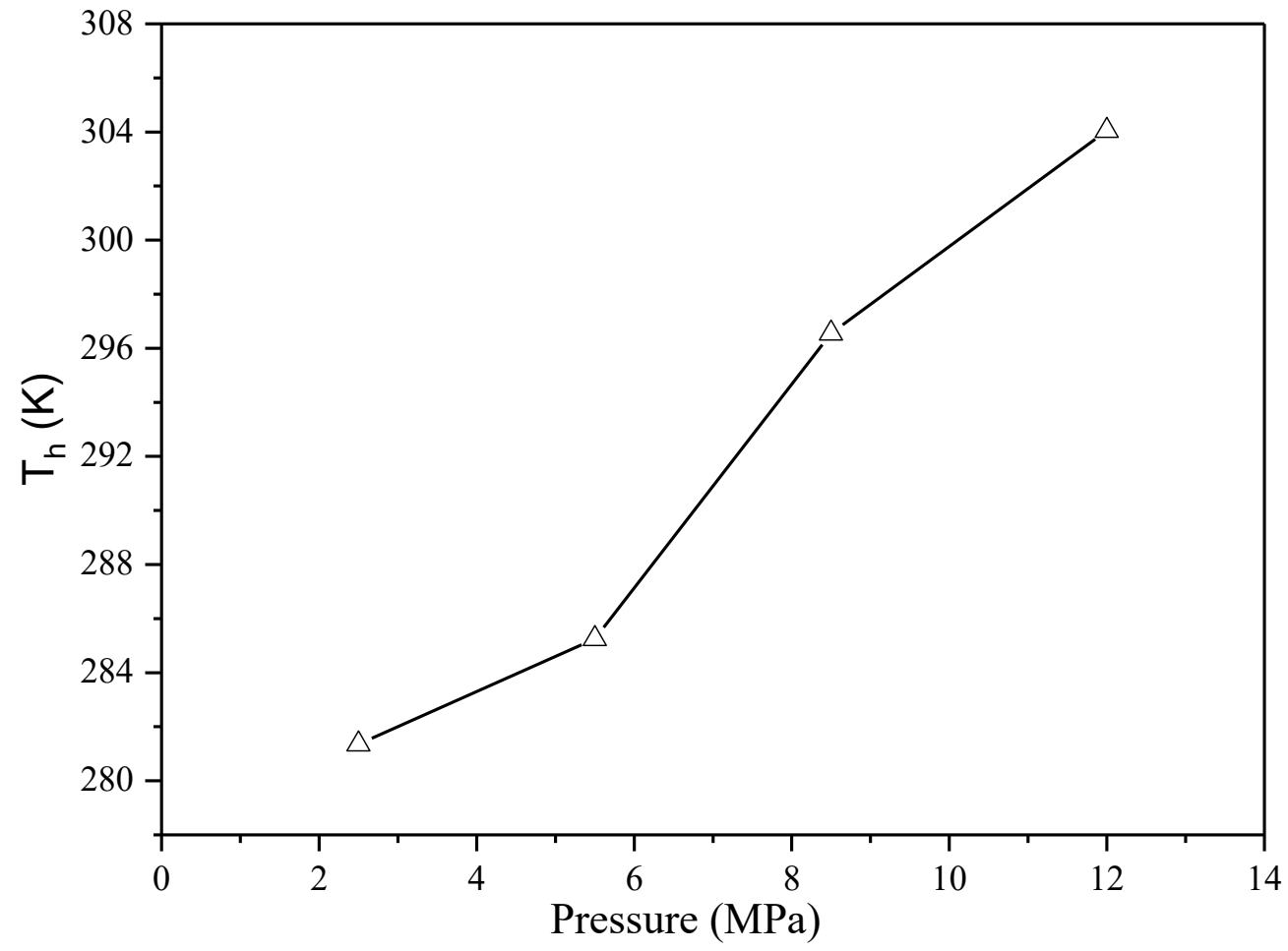

Fig. 10. The highest hydrate slurry temperature $\left(T_{h}\right)$ obtained in different pressures. 
Table 1. Data of $\Delta \mathrm{T}_{\max }$ and positions of gas/liquid $\mathrm{CP}$ interface and liquid/water interface under different conditions.

\begin{tabular}{|c|c|c|c|c|c|c|}
\hline Run & $R_{\mathrm{gl}}$ & $R_{\mathrm{v}}$ & Pressure /MPa & Position of gas/LCP interface & Position of LCP/W interface & $T_{h}$ of hydrate slurry \\
\hline 1 & 0.429 & 0.308 & 8.50 & Between $T_{13}$ and $T_{12} / T_{15}$ & Between $\mathrm{T}_{18}$ and $\mathrm{T}_{19}$ & $\overline{\mathrm{T}_{18}}$ \\
\hline 2 & 0.786 & 0.308 & 8.50 & Between $\mathrm{T}_{18}$ and $\mathrm{T}_{17} / \mathrm{T}_{11}$ & Between $T_{21}$ and $T_{10} / T_{20}$ & $\mathrm{~T}_{18}$ \\
\hline 3 & 1.381 & 0.308 & 8.50 & Between $T_{21}$ and $T_{10} / T_{20}$ & Between $T_{9}$ and $T_{8}$ & $\mathrm{~T}_{20}$ \\
\hline 4 & 2.571 & 0.308 & 8.50 & Between $\mathrm{T}_{7}$ and $\mathrm{T}_{8}$ & Between $T_{5}$ and $T_{6}$ & $\mathrm{~T}_{6}$ \\
\hline 5 & 0.786 & $0.077(5 / 65)$ & 8.50 & Between $T_{18}$ and $T_{17} / T_{11}$ & Between $\mathrm{T}_{18}$ and $\mathrm{T}_{19}$ & $\mathrm{~T}_{18}$ \\
\hline 6 & 0.786 & $0.167(10 / 60)$ & 8.50 & Between $T_{18}$ and $T_{17} / T_{11}$ & Between $T_{19}$ and $T_{20} / T_{10}$ & $\mathrm{~T}_{18}$ \\
\hline 7 & 0.786 & $0.400(20 / 50)$ & 8.50 & Between $T_{18}$ and $T_{17} / T_{11}$ & Between $T_{21}$ and $T_{22}$ & $\mathrm{~T}_{19}$ \\
\hline 8 & 0.786 & $0.556(25 / 45)$ & 8.50 & Between $T_{18}$ and $T_{17} / T_{11}$ & Between $T_{9}$ and $T_{22}$ & $\mathrm{~T}_{20}$ \\
\hline 9 & 0.786 & $0.308(16.5 / 53.5)$ & 2.50 & Between $T_{18}$ and $T_{17} / T_{11}$ & Between $T_{21}$ and $T_{10} / T_{20}$ & $\mathrm{~T}_{18}$ \\
\hline 10 & 0.786 & 0.308 & 5.50 & Between $T_{18}$ and $T_{17} / T_{11}$ & Between $T_{21}$ and $T_{10} / T_{20}$ & $\mathrm{~T}_{18}$ \\
\hline 11 & 0.786 & 0.308 & 12.00 & Between $T_{18}$ and $T_{17} / T_{11}$ & Between $T_{21}$ and $T_{10} / T_{20}$ & $\mathrm{~T}_{18}$ \\
\hline
\end{tabular}

Table 2. Data of $\mathrm{T}_{\mathrm{h}}$ and $\Delta \mathrm{T}_{\max }$ obtained at different position under the condition with $R_{\mathrm{v}}$ of 0.556 and $R_{\mathrm{gl}}$ of 0.786 at $278.15 \mathrm{~K}$ and $8.50 \mathrm{MPa}$.

\begin{tabular}{llllllllllll}
\hline $\mathrm{T}_{\mathrm{i}}$ & $\mathrm{T}_{1}$ & $\mathrm{~T}_{2}$ & $\mathrm{~T}_{3}$ & $\mathrm{~T}_{4}$ & $\mathrm{~T}_{5}$ & $\mathrm{~T}_{6}$ & $\mathrm{~T}_{7}$ & $\mathrm{~T}_{8}$ & $\mathrm{~T}_{9}$ & $\mathrm{~T}_{10}$ & $\mathrm{~T}_{11}$ \\
\hline $\mathrm{T}_{\mathrm{h}-\mathrm{i}}(\mathrm{K})$ & 280.22 & 281.09 & 281.57 & 282.82 & 284.59 & 286.33 & 286.97 & 287.03 & 287.10 & 290.43 & 285.60 \\
$\Delta \mathrm{T}_{\text {max-i }}(\mathrm{K})$ & 3.07 & 3.94 & 4.42 & 5.67 & 7.44 & 9.18 & 9.82 & 9.88 & 9.95 & 13.28 & 8.45 \\
\hline $\mathrm{T}_{\mathrm{i}}$ & $\mathrm{T}_{12}$ & $\mathrm{~T}_{13}$ & $\mathrm{~T}_{14}$ & $\mathrm{~T}_{15}$ & $\mathrm{~T}_{16}$ & $\mathrm{~T}_{17}$ & $\mathrm{~T}_{18}$ & $\mathrm{~T}_{19}$ & $\mathrm{~T}_{20}$ & $\mathrm{~T}_{21}$ & $\mathrm{~T}_{22}$ \\
\hline $\mathrm{T}_{\mathrm{h}-\mathrm{i}}(\mathrm{K})$ & 284.62 & 286.14 & 286.43 & 281.33 & 283.88 & 284.25 & 287.99 & 286.28 & 292.04 & 288.08 & 286.42 \\
$\Delta \mathrm{T}_{\text {max-i }}(\mathrm{K})$ & 7.47 & 8.99 & 9.28 & 4.18 & 6.73 & 7.10 & 10.84 & 9.13 & 14.89 & 10.93 & 9.27 \\
\hline
\end{tabular}


Table 3. Data of $\Delta T_{\max }$ for each thermal couple in the process of hydrate formation under different volume ratio of $C P$ to water $\left(R_{\mathrm{v}}\right)$.

\begin{tabular}{llllllllllll}
\hline$R_{\mathrm{v}} \Delta \mathrm{T}_{\max }$ for $\mathrm{T}_{\mathrm{i}}(\mathrm{K})$ & $\mathrm{T}_{1}$ & $\mathrm{~T}_{2}$ & $\mathrm{~T}_{3}$ & $\mathrm{~T}_{4}$ & $\mathrm{~T}_{5}$ & $\mathrm{~T}_{6}$ & $\mathrm{~T}_{7}$ & $\mathrm{~T}_{8}$ & $\mathrm{~T}_{9}$ & $\mathrm{~T}_{10}$ & $\mathrm{~T}_{11}$ \\
\hline 0.077 & 1.49 & 1.85 & 1.77 & 2.44 & 3.01 & 3.61 & 4.3 & 5.55 & 7.64 & 9.68 & 12.5 \\
0.167 & 1.78 & 2.12 & 2.33 & 2.59 & 3.06 & 3.64 & 4.46 & 5.72 & 7.59 & 11.25 & 11.11 \\
0.308 & 3.18 & 3.88 & 4.61 & 5.55 & 6.77 & 7.90 & 9.08 & 9.25 & 9.64 & 11.82 & 9.91 \\
0.400 & 1.68 & 2.62 & 2.57 & 3.39 & 4.21 & 5.32 & 7.34 & 8.94 & 9.64 & 10.64 & 7.32 \\
0.556 & 3.07 & 3.94 & 4.42 & 5.67 & 7.44 & 9.18 & 9.82 & 9.88 & 9.95 & 13.28 & 8.45 \\
\hline$R_{\mathrm{V}} \Delta \mathrm{T}_{\max }$ for $\mathrm{T}_{\mathrm{i}}(\mathrm{K})$ & $\mathrm{T}_{12}$ & $\mathrm{~T}_{13}$ & $\mathrm{~T}_{14}$ & $\mathrm{~T}_{15}$ & $\mathrm{~T}_{16}$ & $\mathrm{~T}_{17}$ & $\mathrm{~T}_{18}$ & $\mathrm{~T}_{19}$ & $\mathrm{~T}_{20}$ & $\mathrm{~T}_{21}$ & $\mathrm{~T}_{22}$ \\
\hline 0.077 & 8.78 & 9.12 & 10.16 & 5.62 & 10.44 & 9.39 & 17.18 & 14.55 & 12.66 & 10.41 & 10.36 \\
0.167 & 8.02 & 10.24 & 11.52 & 4.77 & 8.14 & 11.19 & 19.24 & 12.22 & 15.86 & 12.46 & 9.79 \\
0.308 & 7.70 & 7.88 & 8.25 & 4.80 & 7.93 & 10.15 & 19.47 & 16.09 & 14.51 & 12.51 & 11.7 \\
0.400 & 7.51 & 8.68 & 9.4 & 4.42 & 6.89 & 7.22 & 8.7 & 16.95 & 12.73 & 10.38 & 10.18 \\
0.556 & 7.47 & 8.99 & 9.28 & 4.18 & 6.73 & 7.1 & 10.84 & 9.13 & 14.89 & 10.93 & 9.27 \\
\hline
\end{tabular}

Table 4. Data of $\Delta \mathrm{T}_{\max }$ for each thermal couple in the process of hydrate formation under different gas/liquid ratio $\left(R_{\mathrm{gl}}\right)$.

\begin{tabular}{|c|c|c|c|c|c|c|c|c|c|c|c|}
\hline$R_{\mathrm{g}} \backslash \Delta \mathrm{T}_{\max }$ for $\mathrm{T}_{\mathrm{i}}(\mathrm{K})$ & $\mathrm{T}_{1}$ & $\mathrm{~T}_{2}$ & $T_{3}$ & $\mathrm{~T}_{4}$ & $\mathrm{~T}_{5}$ & $\mathrm{~T}_{6}$ & $\mathrm{~T}_{7}$ & $T_{8}$ & $\mathrm{~T}_{9}$ & $T_{10}$ & $\mathrm{~T}_{11}$ \\
\hline 0.429 & 1.51 & 2.04 & 1.86 & 2.08 & 2.34 & 0.68 & 3.07 & 3.57 & 4.26 & 8.97 & 10.55 \\
\hline 0.786 & 3.18 & 3.88 & 4.61 & 5.55 & 6.77 & 7.90 & 9.08 & 9.25 & 9.64 & 11.82 & 9.91 \\
\hline 1.381 & 4.98 & 7.18 & 7.88 & 6.95 & 8.84 & 11.41 & 12.31 & 12.33 & 13.46 & 13.48 & 8.21 \\
\hline 2.571 & 9.68 & 8.91 & 9.87 & 9.82 & 12.76 & 14.07 & 13.12 & 12.59 & 13.19 & 7.65 & 8.84 \\
\hline$\widetilde{R_{\mathrm{gl}}} \Delta \mathrm{T}_{\max }$ for $\mathrm{T}_{\mathrm{i}}(\mathrm{K})$ & $\mathrm{T}_{12}$ & $\mathrm{~T}_{13}$ & $\mathrm{~T}_{14}$ & $\mathrm{~T}_{15}$ & $\mathrm{~T}_{16}$ & $\mathrm{~T}_{17}$ & $\mathrm{~T}_{18}$ & $\mathrm{~T}_{19}$ & $\mathrm{~T}_{20}$ & $\mathrm{~T}_{21}$ & $\mathrm{~T}_{22}$ \\
\hline 0.429 & 6.88 & 7.29 & 7.65 & 6.29 & 9.33 & 8.38 & 15.59 & 14.95 & 10.54 & 7.82 & 6.81 \\
\hline 0.786 & 7.70 & 7.88 & 8.25 & 4.80 & 7.93 & 10.15 & 19.47 & 16.09 & 14.51 & 12.51 & 11.7 \\
\hline 1.381 & 8.11 & 8.44 & 8.74 & 4.35 & 6.3 & 6.89 & 9.27 & 8.10 & 15.32 & 12.52 & 11.27 \\
\hline 2.571 & 8.66 & 8.88 & 8.34 & 4.52 & 6.43 & 6.78 & 10.28 & 8.77 & 9.06 & 7.25 & 6.70 \\
\hline
\end{tabular}


Table 5. Data of $\Delta \mathrm{T}_{\max }$ for each thermal couple in the process of hydrate formation under different pressures.

\begin{tabular}{|c|c|c|c|c|c|c|c|c|c|c|c|}
\hline $\begin{array}{l}\mathrm{P} \triangle \mathrm{T}_{\max } \text { for } \mathrm{T}_{\mathrm{i}}(\mathrm{K}) \\
(\mathrm{MPa})\end{array}$ & $\mathrm{T}_{1}$ & $\mathrm{~T}_{2}$ & $T_{3}$ & $\mathrm{~T}_{4}$ & $T_{5}$ & $\mathrm{~T}_{6}$ & $\mathrm{~T}_{7}$ & $\mathrm{~T}_{8}$ & $\mathrm{~T}_{9}$ & $\mathrm{~T}_{10}$ & $\mathrm{~T}_{11}$ \\
\hline 2.50 & 0.81 & 0.96 & 0.96 & 0.85 & 0.9 & 0.96 & 1.03 & 1.11 & 1.2 & 1.87 & 2.49 \\
\hline 5.50 & 0.74 & 0.79 & 0.91 & 0.72 & 0.78 & 0.89 & 1.05 & 1.18 & 1.34 & 3.29 & 5.85 \\
\hline 8.50 & 3.18 & 3.88 & 4.61 & 5.55 & 6.77 & 7.90 & 9.08 & 9.25 & 9.64 & 11.82 & 9.91 \\
\hline 12.00 & 5.67 & 7.66 & 9.34 & 10.46 & 12.43 & 12.82 & 13.48 & 17.46 & 16.32 & 15.99 & 16.9 \\
\hline $\mathrm{PPa}_{(\mathrm{MPa})}^{\Delta \mathrm{T}_{\max } \text { for } \mathrm{T}_{\mathrm{i}}(\mathrm{K})}$ & $\mathrm{T}_{12}$ & $\mathrm{~T}_{13}$ & $\mathrm{~T}_{14}$ & $\mathrm{~T}_{15}$ & $\mathrm{~T}_{16}$ & $\mathrm{~T}_{17}$ & $\mathrm{~T}_{18}$ & $\mathrm{~T}_{19}$ & $T_{20}$ & $\mathrm{~T}_{21}$ & $T_{22}$ \\
\hline 2.50 & 6.84 & 9.84 & 11.63 & 1.5 & 2.12 & 2.25 & 4.3 & 3.32 & 3.76 & 2.03 & 0.81 \\
\hline 5.50 & 7.13 & 8.44 & 9.19 & 2.78 & 4.17 & 5.67 & 8.13 & 4.77 & 3.37 & 2.66 & 0.74 \\
\hline 8.50 & 7.70 & 7.88 & 8.25 & 4.80 & 7.93 & 10.15 & 19.47 & 16.02 & 14.52 & 12.51 & 11.7 \\
\hline 12.00 & 9.82 & 10.2 & 9.82 & 7.19 & 10.75 & 12.64 & 26.94 & 16.2 & 19.57 & 17.34 & 16.85 \\
\hline
\end{tabular}

